\title{
Projection-Specific Neuromodulation of Medial Prefrontal Cortex Neurons
}

\author{
Nikolai C. Dembrow, Raymond A. Chitwood, and Daniel Johnston \\ Center for Learning and Memory, The University of Texas at Austin, Austin, Texas 78712
}

\begin{abstract}
Mnemonic persistent activity in the prefrontal cortex (PFC) constitutes the neural basis of working memory. To understand how neuromodulators contribute to the generation of persistent activity, it is necessary to identify the intrinsic properties of the layer $V$ pyramidal neurons that transfer this information to downstream networks. Here we show that the somatic dynamic and integrative properties of layer V pyramidal neurons in the rat medial PFC depend on whether they project subcortically to the pons [corticopontine (CPn)] or to the contralateral cortex [commissural (COM)]. CPn neurons display low temporal summation and accelerate in firing frequency when depolarized, whereas $\mathrm{COM}$ neurons have high temporal summation and display spike frequency accommodation. In response to dynamic stimuli, COM neurons act as low-pass filters, whereas CPn neurons act as bandpass filters, resonating in the theta frequency range (3-6 $\mathrm{Hz}$ ). The disparate subthreshold properties of COM and CPn neurons can be accounted for by differences in the hyperpolarizationactivated cyclic nucleotide gated cation $\mathrm{h}$-current. Interestingly, neuromodulators hypothesized to enhance mnemonic persistent activity affect COM and CPn neurons distinctly. Adrenergic modulation shifts the dynamic properties of CPn but not COM neurons and increases the excitability of $\mathrm{CPn}$ neurons significantly more than $\mathrm{COM}$ neurons. In response to cholinergic modulation, $\mathrm{CPn}$ neurons were much more likely to display activity-dependent intrinsic persistent firing than COM neurons. Together, these data suggest that the two categories of projection neurons may subserve separate functions in PFC and may be engaged differently during working memory processes.
\end{abstract}

\section{Introduction}

During higher-order executive tasks that engage working memory, the prefrontal cortex (PFC) exerts top-down control, coordinating activity in downstream networks via extensive connections to cortical and subcortical targets (Miller, 2000; Narayanan and Laubach, 2006; Arnsten, 2007). PFC dysfunction contributes to cognitive and behavioral impairments associated with Tourette's syndrome, posttraumatic stress disorder, attention-deficit hyperactivity disorder, and schizophrenia (Bremner et al., 1999; Shin et al., 2004; Casey et al., 2007; Marsh et al., 2007; Bonilha et al., 2008; Lewis and González-Burgos, 2008). Neuromodulatory regulation of PFC function is a target of both the pathology and treatment of these disorders (Hyde and Crook, 2001; Bymaster and Felder, 2002; Kapur, 2003; Arnsten, 2004, 2006; Ikonomovic et al., 2007; Strawn and Geracioti, 2008; Dopheide and Pliszka, 2009; Scahill, 2009). Within animal models, task performance and mnemonic persistent activity of PFC are also sensitive to neuromodulation (Herremans et al., 1997; Wall et al., 2001; Chudasama et al., 2004; Vijayraghavan et al., 2007; Wang et al., 2007). Elucidating how neuromodulation affects

Received July 12, 2010; revised Aug. 31, 2010; accepted 0ct. 8, 2010.

This project was supported by National Institutes of Health Grant MH048432 (D.J.). Sincere thanks to Jeffery Drucker, Ryan Robertson, and Rachna Patel for histological processing and morphological reconstructions and Vicky Maria Moya for processing and cataloguing cannula track placements. Thanks to Rishikesh Narayanan, Payne Chang, Kevin Dougherty, Sachin Vaidya, Brian Kalmbach, and Darrin Brager for their helpful comments on this manuscript. Correspondence should be addressed to Nikolai C. Dembrow, Center for Learning and Memory, The University of Texas at Austin, 1 University Station Stop 77000 Austin, TX 78712-0805. E-mail: nikolai@mail.clm.utexas.edu. DOI:10.1523/JNEUROSCI.3644-10.2010

Copyright $\odot 2010$ the authors $\quad 0270-6474 / 10 / 3016922-16 \$ 15.00 / 0$ mnemonic activity in PFC may require understanding how it modifies the communication of PFC to downstream networks.

A primary source of output from the PFC occurs via layer $\mathrm{V}$ pyramidal neurons. Neuromodulation of synaptic inputs to these neurons (Law-Tho et al., 1993; Couey et al., 2007; Wang et al., 2008; Kruse et al., 2009) and their intrinsic properties have been characterized, with some conflicting results (McCormick and Prince, 1985; Haj-Dahmane and Andrade, 1996, 1998, 1999; Yang and Seamans, 1996; Gulledge and Jaffe, 1998, 2001; Gulledge and Stuart, 2003; Carr et al., 2007; Carr and Surmeier, 2007; Gulledge et al., 2007). One potential explanation for these discrepancies may be the diversity of layer $\mathrm{V}$ pyramidal neuron types. In several neocortical regions, including the rat dorsal medial PFC ( $\mathrm{mPFC}$ ), layer $\mathrm{V}$ pyramidal neurons have distinct interconnectivity, morphology, and firing patterns depending on their long-range projection targets (Molnár and Cheung, 2006; Morishima and Kawaguchi, 2006; Otsuka and Kawaguchi, 2008; Brown and Hestrin, 2009). Comparing the neuromodulatory responses of mPFC neurons with distinct projection targets remains unexplored.

Here we report that the subthreshold and suprathreshold integration of layer $\mathrm{V}$ pyramidal neurons in the rat ventral $\mathrm{mPFC}$ depend on their long-range projection targets. The distinct responses of neurons that project to the pons [corticopontine $(\mathrm{CPn})]$ and neurons that project to the contralateral cortex [commissural (COM)] to dynamic subthreshold stimuli can be abolished by blocking the hyperpolarization-activated cyclic nucleotide-gated cation h-current. Consequently, $\alpha 2$ adrenergic and cholinergic modulation, which modify h-currents 
(Carr et al., 2007; Wang et al., 2007; Barth et al., 2008; Heys et al., 2010), alter the dynamic and integrative properties of CPn but not COM neurons. Additionally, intrinsic properties not accounted for by the h-current were also unique between COM and $\mathrm{CPn}$ neurons. CPn, but not COM, neurons reliably display activity-dependent persistent firing in the presence of cholinergic agonists. With such disparate integrative properties and responses to neuromodulation, CPn and COM neurons may contribute in different ways to mnemonic persistent activity.

\section{Materials and Methods}

Bead infusions. All surgical methods were approved by The University of Texas at Austin Institutional Animal Care and Use Committee. Male Sprague Dawley rats 4-8 weeks old were anesthetized with a ketamine $(90 \mathrm{mg} / \mathrm{kg}) / x y l a z i n e(10 \mathrm{mg} / \mathrm{kg})$ mixture. Retrogradely transported fluorescently labeled microspheres (Red or Green Retrobeads; Lumafluor) were infused stereotaxically into either the contralateral PFC $(3.0 \mathrm{~mm}$ anterior to bregma, $1.0 \mathrm{~mm}$ lateral to bregma, $4.0 \mathrm{~mm}$ ventral to bregma) or into the ipsilateral (left) pontine nuclei and surrounding pyramidal tracts $(6.8-7.2 \mathrm{~mm}$ posterior to bregma, $2.0 \mathrm{~mm}$ lateral to bregma, 9-9.8 $\mathrm{mm}$ ventral to bregma). Infusions were performed using 33 gauge infusion cannula that extended $1.2 \mathrm{~mm}$ and was held in place by 26 gauge stainless-steel guide cannula (Plastics One), connected to a $10 \mu \mathrm{l} \mathrm{Ham}-$ ilton syringe driven by an automated injector system (model MD-1001; Bioanalytical Systems) and electronic pump (model MD-1020) infused at the rate of $0.05 \mu \mathrm{l} / \mathrm{min}$. After infusion of $0.5-1 \mu \mathrm{l}$, the infusion rate was slowed to $0.005 \mu \mathrm{l} / \mathrm{min}$ for $10 \mathrm{~min}$ before removing the cannulae. Animals were allowed to recover a minimum of $2 \mathrm{~d}$ before use in physiology experiments.

Slice preparation. Male Sprague Dawley rats 5-16 weeks old were anesthetized with a ketamine $(160 \mathrm{mg} / \mathrm{kg}) / x y l a z i n e ~(16 \mathrm{mg} / \mathrm{kg})$ mixture and intracardially perfused with ice-cold, artificial CSF (aCSF) consisting of the following (in mM): $2.5 \mathrm{KCl}, 1.25 \mathrm{NaH}_{2} \mathrm{PO}_{4}, 25 \mathrm{NaHCO}_{3}, 0.5 \mathrm{CaCl}_{2}, 7$ $\mathrm{MgCl}_{2}, 7$ dextrose, 205 sucrose, 1.3 ascorbic acid, and 3 sodium pyruvate (bubbled with $95 \% \mathrm{O}_{2} / 5 \% \mathrm{CO}_{2}$ to maintain a $\mathrm{pH}$ of $\sim 7.4$ ). Brains were removed, and a blocking cut was made at approximately $-2.5 \mathrm{~mm}$ posterior to bregma near coronally to maximize the dendritic projections of the left hemisphere within the plane of the slice. The front half of the brain was mounted on the cut surface, rostral end up with the dorsal side toward the blade and sliced on a vibrating tissue slicer (Vibratome 3000; Vibratome Inc.). Coronal slices were cut $300 \mu \mathrm{m}$ thick and held for $\sim 30$ min at $37^{\circ} \mathrm{C}$ in a holding chamber of aCSF solution containing the following (in mM): $125 \mathrm{NaCl}, 2.5 \mathrm{KCl}, 1.25 \mathrm{NaH}_{2} \mathrm{PO}_{4}, 25 \mathrm{NaHCO}_{3}, 2 \mathrm{CaCl}_{2}$, $1 \mathrm{MgCl}_{2}, 10$ dextrose, 1.3 ascorbic acid, and 3 sodium pyruvate (bubbled with $\left.95 \% \mathrm{O}_{2} / 5 \% \mathrm{CO}_{2}\right)$. Afterward, slices were stored at room temperature $\left(\sim 22^{\circ} \mathrm{C}\right)$ until time of recording.

Whole-cell recordings. Whole-cell current-clamp recordings were performed on slices submerged in a chamber filled with aCSF heated to $32-34^{\circ} \mathrm{C}$ flowing at a rate of $1-2 \mathrm{ml} / \mathrm{min}$ in recording solution, which was identical to the holding solution but with the addition of the following (in $\mathrm{mm}$ ): $0.5 \mathrm{KCl}, 0.01 \mathrm{CNQX}, 0.05 \mathrm{APV}, 0.01$ bicuculline, 0.01 picrotoxin. In some experiments, $0.02 \mathrm{~mm}$ DNQX was substituted for CNQX, and $0.02 \mathrm{~mm}$ gabazine was substituted for bicuculline and picrotoxin. Neurons were visualized using either a standard upright microscope (Carl Zeiss FS-1) fitted with differential interference contrast optics using infrared illumination (Stuart et al., 1993) or a two-photon laser scanning microscope (Leica SP5-RS) using Dodt contrast (Dodt and Zieglgänsberger, 1990). Bead-labeled neurons were identified using either the two-photon excitation at $840 \mathrm{~nm}$ or excited via a mercury lamp filtered through a $540 \mathrm{~nm} / 605 \mathrm{~nm}$ excitation/emission filter. Patch pipettes (4-7 $\mathrm{M} \Omega$ ) were pulled from capillary glass of external diameter $1.65 \mathrm{~mm}$ (World Precision Instruments) using a Flaming/Brown micropipette puller (model P-97, Sutter Instruments) and filled with an internal solution containing the following (in $\mathrm{mm}$ ): $120 \mathrm{~K}$-gluconate, $20 \mathrm{KCl}, 10$ HEPES, 4-8 NaCl, $7 \mathrm{~K}_{2}$-phosphocreatine, $0.3 \mathrm{Na}$-GTP, and $4 \mathrm{Mg}$-ATP. Neurobiotin (Vector Laboratories) was included (0.1-0.2\%) for subsequent histological processing. Data were acquired with either a Multiclamp 700B amplifier (Molecular Devices) and Axograph 6.0 (AxoGraph
A
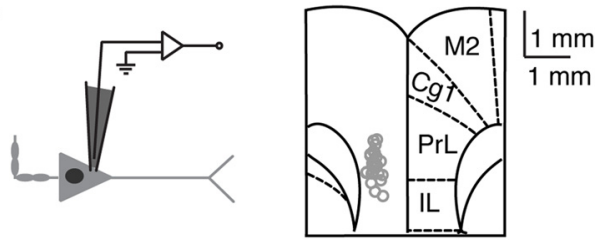

B
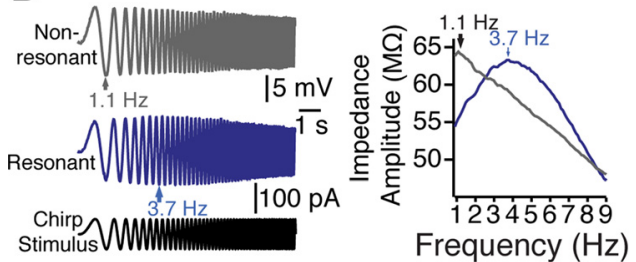

C

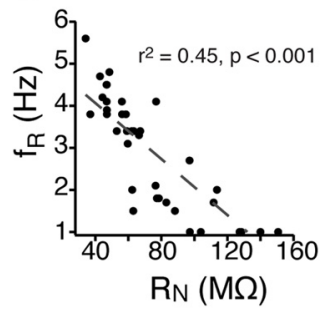

D

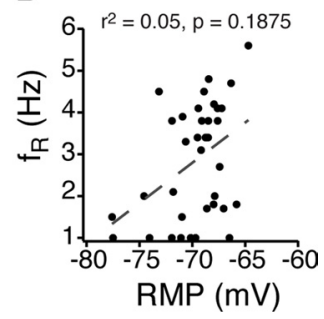

Figure 1. Heterogeneity in the dynamic properties of $\mathrm{mPFC}$ neurons. $\boldsymbol{A}$, Somatic recordings of layer V mPFC neurons were conducted within ventral mPFC, including prelimbic and infralimbic cortex. Left, A schematic of an mPFC neuron and the somatic recording location. Right, Recording locations overlaid with a modified version of a coronal diagram from a rat brain atlas (Paxinos and Watson, 1993). $\boldsymbol{B}$, In response to a $10 \mathrm{~s}$ chirp stimulus at their resting membrane potential, different $m$ PFC neurons resonated across a range $(1-6 \mathrm{~Hz})$ of frequencies. $\boldsymbol{C}, \boldsymbol{D}$, In addition to exhibiting different resonance profiles, neurons were diverse in both steady-state input resistance (C) and resting membrane potential ( $\boldsymbol{D})(n=38$ neurons). Gray dashed lines represent the linear fit of the data, with correlation values listed. PL, Prelimbic; IL, infralimbic; Cg1, anterior cingulate; M2, secondary motor cortices.

Scientific) acquisition software or a Dagan BVC-700 amplifier with custom-written acquisition software in the IgorPro environment (Wavemetrics). All data were acquired at $20-50 \mathrm{kHz}$ using an ITC-18 (InstruTech) and filtered at $5-20 \mathrm{kHz}$. All drugs were made up as $1000 \times$ stock solutions in water, equivalent $\mathrm{NaOH}$, or DMSO (final concentration of DMSO $\leq 0.1 \%$ ). Five to $10 \mathrm{~min}$ were allowed for solutions to wash in before taking measurements. Pipette capacitance was compensated for, and the bridge was balanced before each recording. Voltages are not corrected for liquid junction potential, which is $7-8 \mathrm{mV}$ based on previous results (Rosenkranz and Johnston, 2007; Narayanan and Johnston, 2008). Series resistance was $8-25 \mathrm{M} \Omega$ for all recordings, and experiments were terminated if this range was exceeded.

Reconstructions. Slices were fixed in 3\% glutaraldehyde in $0.1 \mathrm{M}$ phosphate buffer, $\mathrm{pH} 7.4$, and stored at $4^{\circ} \mathrm{C}$ for up to 3 months. Slices were processed using an avidin-HRP system activated by diaminobenzidine (DAB) (Vector Laboratorties). DAB-processed slices were mounted in glycerol and viewed with a compound (Leitz Diaplan) microscope. Somatic locations of neurons (Fig. $1 \mathrm{~A}$ ) were measured relative to the intersection of the midline and the apex of dorsal surface using Neurolucida 6.0 imaging software (MicroBrightField). Neurons were reconstructed using a $40 \times$ objective with a computer-controlled indexing system running Neurolucida. Cell morphology measurements, including dendritic length, surface area and volume, and Sholl analyses (Sholl, 1953), were measured using Neurolucida Explorer.

Data analysis. Input resistance was calculated as the slope of the linear fit of the voltage-current plot generated from a family of current injections. The membrane time constant was calculated as the slow component of a double-exponential fit of the average voltage decay resulting from alternating depolarizing and hyperpolarizing current injections 
(400 pA, $1 \mathrm{~ms}$ ). Single action potentials (APs) were analyzed for AP threshold, maximum $d v / d t$ (millivolts per milliseconds), AP peak, AP amplitude, and AP half-width. Threshold was defined as the voltage at the time corresponding to the first maximum of the third derivative of the voltage response. Action potential amplitude was measured from threshold to peak, with the half-width measured at half this distance. The sag ratio was calculated as the proportional difference between maximum and steady-state voltage transients resulting from hyperpolarizing current injections. Rebound was measured as the slope of the rebound potential amplitude as a function of the steady-state voltage. Resonance was measured using a sinusoidal current injection of constant amplitude and linearly spanning $0-10 \mathrm{~Hz}$ in $10 \mathrm{~s}, 0-15 \mathrm{~Hz}$ in $15 \mathrm{~s}$, or $0-20 \mathrm{~Hz}$ in $20 \mathrm{~s}$, and the impedance amplitude profile (ZAP) was determined by taking the ratio of the fast Fourier transform of the voltage response to the fast Fourier transform of the stimulus (Puil et al., 1986; Narayanan and Johnston, 2007). Resonance frequency was defined as the peak of the ZAP and resonance strength the ratio of the peak impedance to the impedance at $1 \mathrm{~Hz}$.

Statistical analyses. Discriminant cluster analysis was performed to identify whether neuron types could be sorted by different electrophysiological parameters. Differences were assessed using either Student's $t$ test or in cases with more than one group ANOVA, followed by Student's $t$ tests with Bonferroni's correction to account for within-group effects. For paired data, repeated-measures ANOVA or two-factor mixed ANOVA were performed, as specified. When SDs across groups were significantly different according to Bartlett's test, a Dunn-corrected, nonparametric ANOVA (Kruskal-Wallis) test was used instead. Statistical analyses were performed in JMP (SAS Institute), InStat (GraphPad Software), or Excel (Microsoft). Data are reported as mean \pm SE.

\section{Results}

\section{Both dynamic and steady-state properties of layer V mPFC neurons depend on their long-range projection targets}

One proposed means by which the PFC exerts top-down control over downstream networks is via coherence in the oscillatory dynamics of PFC and its various targets (Engel et al., 2001; Klimesch et al., 2010). The oscillatory dynamics of network activity depend on the dynamic properties of constituent neurons within the network (Marder et al., 1996; Hutcheon and Yarom, 2000). Individual neurons will respond to inputs in a frequencydependent manner depending on the combination of various voltage-gated conductances they express, but in particular the expression of the h-current and M-type $\mathrm{K}^{+}$current (Hutcheon and Yarom, 2000; Hu et al., 2002, 2007, 2009; Narayanan and Johnston, 2007, 2008). Thus, the membrane voltage will resonate with inputs of a particular frequency domain, while filtering out inputs at other frequencies. Despite their importance, the dynamic integrative properties of the layer $\mathrm{V}$ pyramidal neurons that provide output from the PFC remain uncharacterized.

We observed considerable heterogeneity in the both the dynamic and steady-state intrinsic properties of layer $\mathrm{V}$ pyramidal neurons in mPFC. Neurons $(n=38)$ displayed a wide range of both resting membrane potential (RMP) $(-60.5$ to $-77.6 \mathrm{mV})$ and steady-state input resistance $\left(R_{\mathrm{N}}\right)(34.2-180.6 \mathrm{M} \Omega)$. To examine subthreshold dynamic properties in mPFC neurons, we injected a sinusoidal current with constant amplitude that linearly increased in frequency (chirp stimulus) into the soma (Fig. $1 A, B)$. Calculating the ZAP in response to the chirp stimulus revealed the varied filtering properties of individual neurons (Fig. $1 C$ ). The resonance frequency, $f_{\mathrm{R}}$ (determined by the peak of the ZAP) ranged from 1.0 to $5.6 \mathrm{~Hz}$, with a resonance strength $(Q)$ of 1.0-1.21. Some neurons acted as low-pass filters, with the largest voltage response occurring at lowest input frequencies. Others exhibited resonance at higher frequencies, acting as bandpass filters with resonance frequencies as high as $5.6 \mathrm{~Hz}$. In general, resonance frequency was correlated with steady-state input resistance $\left(r^{2}=0.45, p<0.001\right)$ but not with resting membrane potential $\left(r^{2}=0.05, p=0.1875\right)$ (Fig. $\left.1 C, D\right)$.

What might account for the heterogeneity in the intrinsic properties of the mPFC layer V pyramidal neurons? One explanation may be the long-range projection targets of the individual neurons. In several cortical regions, including more caudal/dorsal aspects of $\mathrm{mPFC}$, neurons that project subcortically to the pons have distinct morphology and firing properties relative to those that project across the corpus callosum to the contralateral cortex (Wang and McCormick, 1993; Morishima and Kawaguchi, 2006; Hattox and Nelson, 2007; Otsuka and Kawaguchi, 2008; Brown and Hestrin, 2009). This is of particular interest in the context of mnemonic persistent activity because the mPFC projections subcortically to the pons drive activity necessary to facilitate learning in trace eyelid conditioning, which is likely to use delay cell activity in mPFC to associate stimuli separated in time (Kalmbach et al., 2009, 2010). To test whether the dynamic properties of layer $\mathrm{V}$ pyramidal neurons in the $\mathrm{mPFC}$ might correlate with their long-range projection target, we infused vital retrograde tracers (Lumafluor beads) into either: (1) the contralateral cortex or (2) the ipsilateral pons (Fig. $2 A)$. In a subset of rats $(n=$ 2 ), we compared the distribution of neurons that projected to each target by infusing green fluorescent beads in the pons and red fluorescent beads into the contralateral cortex in the same animal. Neurons projecting to the contralateral cortex through the corpus callosum (COM; red) were distributed throughout both the superficial (II-III) and deep (V-VI) layers. Neurons projecting subcortically to the pons (CPn; green) were exclusively in the deep layers (V-VI) of mPFC (Fig. $2 B$ ). For the purposes of this study, we focused exclusively on layer $\mathrm{V}$ projection neurons. In layer $\mathrm{V}$, the $\mathrm{COM}$ and $\mathrm{CPn}$ neurons were in close proximity to one another $(<20 \mu \mathrm{m})$ (Fig. $2 B)$. However, we failed to detect neurons labeled by both tracers, suggesting that, although they overlapped spatially within the mPFC, the two neuronal populations were nevertheless distinct.

Next, we examined whether the layer $\mathrm{V}$ neurons in $\mathrm{mPFC}$ had distinct intrinsic properties depending on their projection target. CPn neurons had on average a lower steady-state $R_{\mathrm{N}}$ compared with COM neurons (CPn, $n=38,50.06 \pm 2.86 \mathrm{M} \Omega$; COM, $n=$ $29,105.63 \pm 7.01 \mathrm{M} \Omega$; Student's unpaired $t$ test, $p<0.001)$. CPn neurons exhibited membrane resonance in response to a chirp stimulus $\left(f_{\mathrm{R}}=3.81 \pm 0.11 \mathrm{~Hz}, Q=1.087 \pm 0.007\right)$, whereas COM neurons were nonresonant $\left(f_{\mathrm{R}}=1.01 \pm 0.08 \mathrm{~Hz}, Q=\right.$ $1.015 \pm .009$; Student's unpaired $t$ test, $p<0.001$ ) (Fig. $2 C, D$ ). $\mathrm{CPn}$ and COM neurons were not significantly different in resting membrane potential (COM, $-68.9 \pm 0.8 \mathrm{mV}$; CPn, $-67.3 \pm 0.3$; Student's $t$ test $p=0.06)$. Among CPn neurons, resonance frequency was still correlated with steady-state input resistance, albeit more weakly $\left(r^{2}=0.24, p<0.05\right)$, but not the resting membrane potential $\left(r^{2}=0.13, p=0.08\right)$. COM neurons exhibited no correlation between resonance frequency and input resistance or membrane potential $\left(R_{\mathrm{N}}\right.$ and $f_{\mathrm{R}}, r^{2}=0.06, p=0.42 ; R_{\mathrm{N}}$ and RMP, $\left.r^{2}=0.01, p<0.72\right)$. Performing discriminant cluster analysis using resting membrane potential, input resistance, and resonance frequency (Fig. $2 E, F$ ) revealed that the two neuronal populations were best distinguished by their resonance frequency ( $F$ ratios from multivariate ANOVA: $f_{\mathrm{R}}=122.24, R_{\mathrm{N}}=2.43$, $\mathrm{RMP}=0.02)$. In a subset of experiments, we recorded from neurons that were not retrogradely labeled from injections in the pons but were within $50 \mu \mathrm{m}$ of labeled CPn neurons $(n=5)$. The intrinsic properties of the unlabeled neurons varied. Some fit 


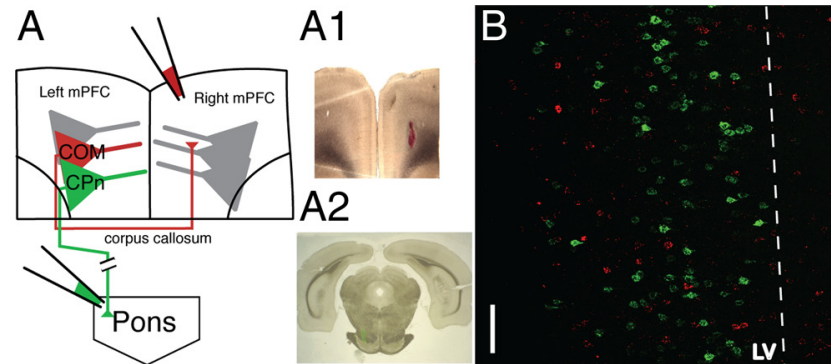

C
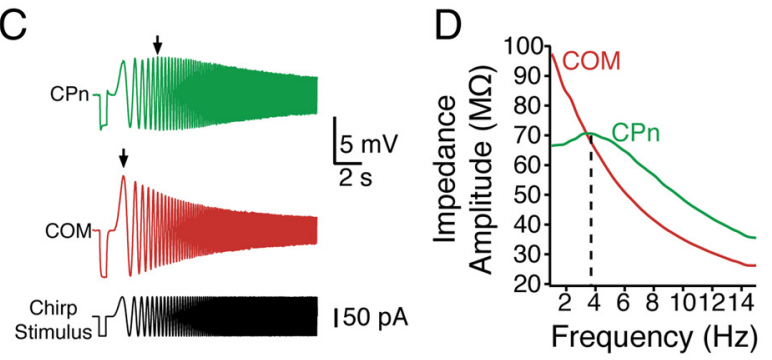

$\mathrm{E}$

F

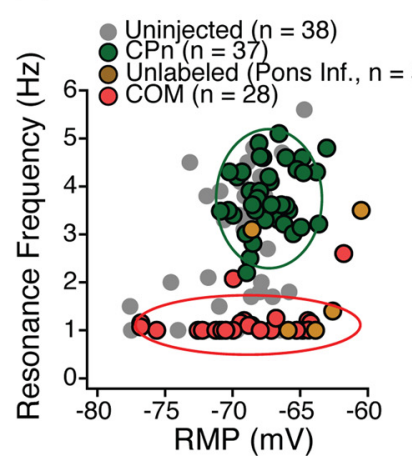

A

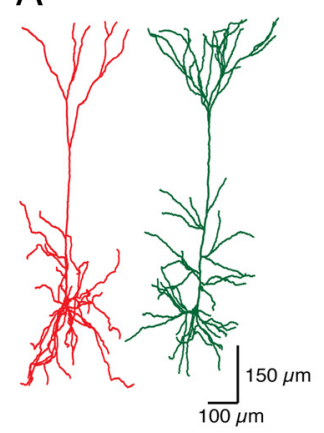

$\mathrm{B}$

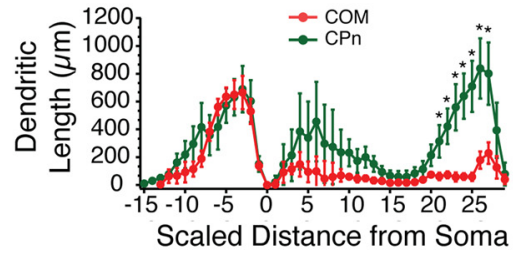

C

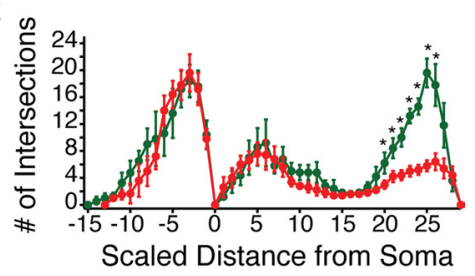

D
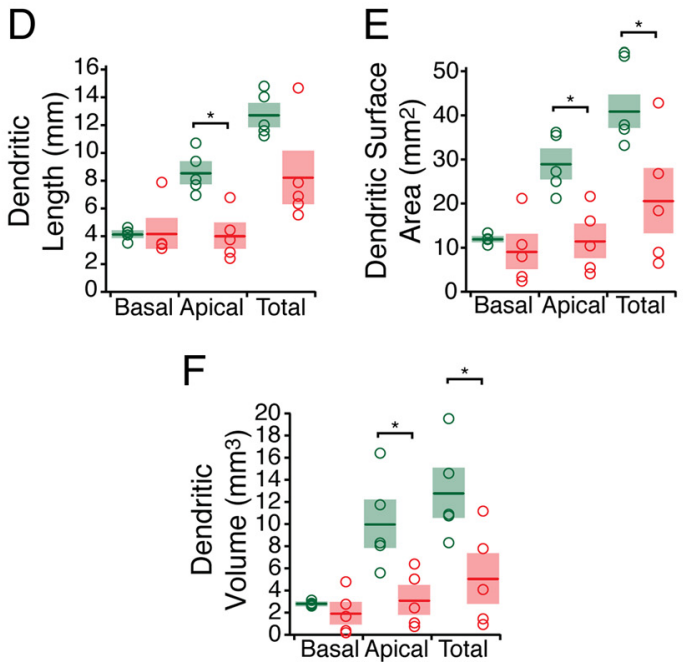

Figure 2. Dynamics of mPFC neurons depend on their long-range projection targets. $\boldsymbol{A}$, Schematic of dual infusion strategy. Retrograde beads were infused into contralateral mPFC and/or the ipsilateral pyramidal tracts/pons. A1, Coronal slice, $300 \mu \mathrm{m}$ thick, containing the contralateral mPFC infusion site. A2, Ipsilateral pyramidal tract infusion site in a $50 \mu \mathrm{m}$ coronal section. $\boldsymbol{B}$, Distribution of COM and $\mathrm{CPn}$ neurons. COM and $\mathrm{CPn}$ neurons are two nonoverlapping populations. (Pn neurons (green) form a band at the upper parts of layer V (LV). COM neurons (red) are interspersed throughout layer $V$ in close proximity to $C P n$ neurons as well as in more superficial layers. Scale bar, $50 \mu \mathrm{m}$. C, In response to a $15 \mathrm{~s}, 15 \mathrm{~Hz}$ chirp stimulus, $(P n$ neurons (green) resonate at a much higher frequency than COM neurons (red). D, A comparison of the ZAP of COM versus (Pn neurons. $E, F$, Overlay of the resonance profiles plotted against membrane potential $(\boldsymbol{E})$ and input resistance $(\boldsymbol{F})$. Neurons were labeled by the pyramidal tract/ pontine infusion (green), neurons did not get labeled by the pontine pyramidal tract/pontine infusion (gold), or COM neurons labeled from the contralateral infusion (red). For comparison, unlabeled neurons from Figure 1, $\mathbf{C}$ and $\boldsymbol{D}$, are shown in gray. Cluster boundaries (solid lines) were found using mean cluster analysis and represent the SD around each cluster.

within the cluster of COM neurons ( 3 of 5), one within the cluster of CPn neurons ( 1 of 5), and one outside either cluster ( 1 of 5).

In other brain regions, neurons that project subcortically to the pons are morphologically distinct from those that project across the corpus callosum (Kasper et al., 1994a,b; Morishima and Kawaguchi, 2006; Hattox and Nelson, 2007; Le Bé et al., 2007; Otsuka and Kawaguchi, 2008). To test whether there were also morphological differences of CPn and COM neurons in ventral mPFC, our electrophysiological measurements were made with Neurobiotin, permitting histological processing and subsequent reconstruction (Fig. 3) ( $n=5$ each group). The somata of CPn neurons were not significantly larger than COM neurons (soma perimeters: CPn, $75.36 \pm 4.92$ vs COM, $68.22 \pm 4.49 \mu \mathrm{m}, p=$ 0.2648 ; soma area: $330.04 \pm 31.68$ vs $259.23 \pm 21.97 \mu \mathrm{m}^{2}, p=$

Figure 3. Representative morphologies of mPFC COM and CPn neurons. $\boldsymbol{A}$, Representative reconstructions from Neurobiotin filled and subsequently DAB processed identified COM (red) and CPn (Green) neurons. B, C, Sholl analysis (grouped into $30 \mu \mathrm{m}$ segments) illustrates the distinct morphology of $\mathrm{COM}(n=5)$ versus $\mathrm{CPn}(n=5)$ neurons in the apical tuft region. $\boldsymbol{D}-\boldsymbol{F}$, Dendritic lengths $(\boldsymbol{D})$, surface area $(\boldsymbol{E})$, and volume $(\boldsymbol{F})$ from the two neuron types. ${ }^{*} p<0.05$.

0.0741; $n=5$ each group). Similar to dorsal PFC, most COM neurons had a simpler dendritic tuft than CPn neurons, although some were qualitatively similar to CPn neurons (Morishima and Kawaguchi, 2006). The origin of the tuft had a tendency to be more proximal to the soma in COM neurons $(334 \pm 53 \mu \mathrm{m})$ than in CPn neurons (500.4 $\pm 58 \mu \mathrm{m})$, but this difference was not statistically significant ( $t$ test, $p=0.68$ ). Sholl analysis revealed that differences in the two neuron types were greater at the end of the apical tuft (ANOVA, $F=30.06, p<0.05$ ). Additionally, the total summed apical dendritic length $(\mathrm{CPn}, 8.58 \pm 0.66 \mathrm{~mm}$; $\mathrm{COM}, 4.05 \pm 0.77 \mathrm{~mm} ; p<0.05)$, surface area $(\mathrm{CPu}, 29.02 \pm$ $2.94 \mathrm{~mm}^{2}$; COM, $11.533 \pm 3.29 \mathrm{~mm}^{2}$ ), and volume (CPn, $10.02 \pm 1.87 \mathrm{~mm}^{3}$; COM, $\left.3.13 \pm 1.11 \mathrm{~mm}^{3} ; p<0.05\right)$ of CPn neurons were all significantly larger than COM neurons.

\section{Distinct subthreshold properties of CPn and COM neurons are dependent on differences in h-current}

Neurons resonate as the result of a combination of inductive and amplifying voltage-sensitive conductances active at rest (Hutcheon and Yarom, 2000). Because CPn and COM neurons had unique resonant properties (Fig. 2), we sought to further examine which voltage sensitive conductances might account for their resonance profiles. To perform more accurate comparisons between neu- 
A

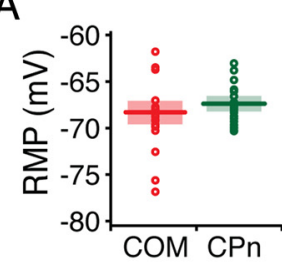

B

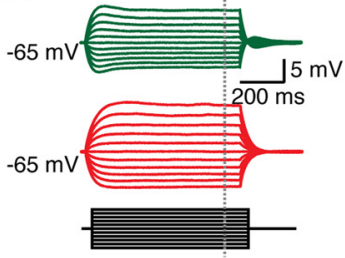

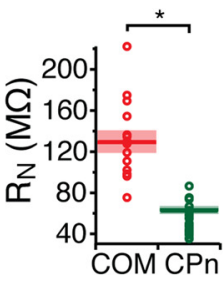
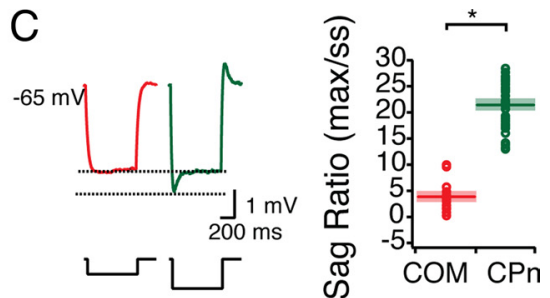

D

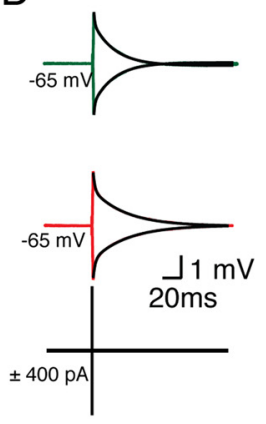

E
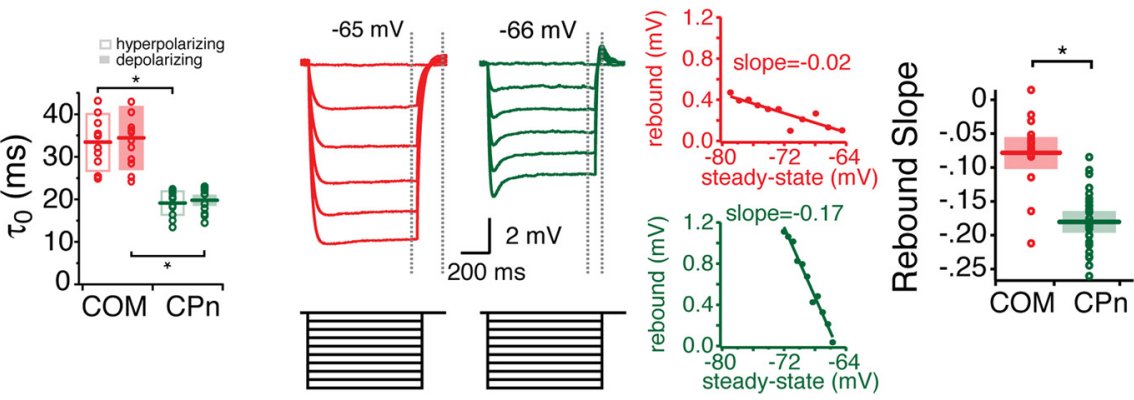

$\mathrm{F}$
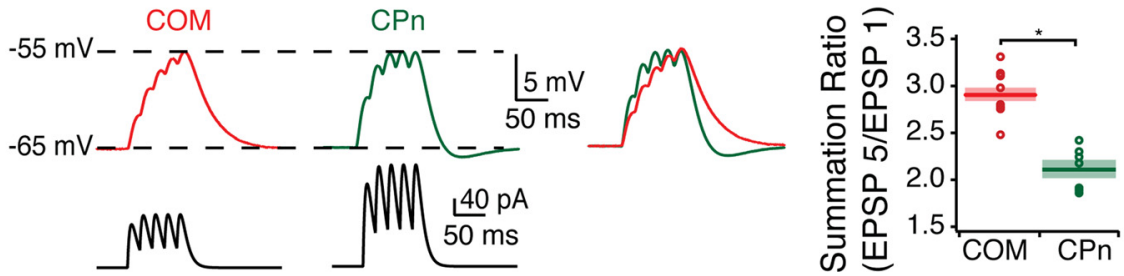

Figure 4. Subthreshold properties of CPn and COM neurons. Somatic patch recordings of labeled COM and CPn neurons reveal that they have distinct subthreshold properties. $A$, $C P n$ neurons are slightly more depolarized than COM neurons, although not significantly. For the purpose of comparison, neurons were held at $-65 \mathrm{mV}$ during stimulus protocols. $\boldsymbol{B}-\boldsymbol{F}$, COM neurons (red) have higher steady-state input resistance $(\boldsymbol{B})$, lower sag ratio $(\boldsymbol{C})$, slower time constant in both the hyperpolarizing and depolarizing directions $(\boldsymbol{D})$, less rebound $(\boldsymbol{E})$, and more temporal summation $(\boldsymbol{F})$ than (Pn neurons (green). ${ }^{*} p<0.05$.

rons, measurements were performed at the same membrane potential. At $-65 \mathrm{mV}, \mathrm{CPn}$ neurons had a lower steady-state input resistance than COM neurons (Fig. 4) $(\mathrm{CPn}, 52.23 \pm 3.68 \mathrm{M} \Omega$; $\mathrm{COM}, 109.93 \pm 5.20 \mathrm{M} \Omega ; p<0.05)$. The functional membrane time constant of CPn neurons was significantly faster than COM neurons (Fig. 4D) (CPn, $19.99 \pm 0.88 \mathrm{~ms}$ depolarizing, $19.36 \pm$ $0.88 \mathrm{~ms}$ hyperpolarizing; COM, $34.45 \pm 2.04 \mathrm{~ms}$ depolarizing, $33.55 \pm 1.94 \mathrm{~ms}$ hyperpolarizing). The $f_{\mathrm{R}}$ and $R_{\mathrm{N}}$ of $\mathrm{CPn}$ and $\mathrm{COM}$ neurons suggested that they may have differences in their h-currents. In agreement with this, we found that CPn neurons had a greater "voltage sag" in response to hyperpolarization (Fig. 4C) (CPn, $21.55 \pm 0.82 \%$; COM, $3.89 \pm 0.68 \%$; $p<0.001$. Another h-current sensitive measure is the slope of the rebound potential plotted as a function of the steady-state voltage potential from a hyperpolarizing current step. In corroboration with other h-current-sensitive measures, CPn neurons expressed a greater rebound slope after release from hyperpolarization than COM neurons (Fig. $4 E$ ) (CPn, $-0.1807 \pm 0.007$; COM, $-0.0773 \pm 0.014 ; p<0.001)$. Some rebound was evident even with very brief $(1 \mathrm{~ms})$ current injections used to measure the functional membrane time constant (Fig. 4D). Differences in h-current should affect subthreshold integration. To test this, we injected $\alpha$ EPSCs into the soma. COM neurons displayed considerably more temporal summation than $\mathrm{CPn}$ neurons (Fig. $4 F$ ) (fifth EPSP/first EPSP; CPn, $2.12 \pm 0.09, n=7$; COM, $2.91 \pm$ $0.07, n=11 ; p<0.01$ ).

To elucidate how voltage-sensitive conductances contribute to the distinct properties of $\mathrm{COM}$ and $\mathrm{CPn}$ neurons, we measured both their dynamic (resonance frequency) and steady-state properties across a range of voltages (Fig. 5) $(-60$ to $-80 \mathrm{mV})$. CPn neurons had a lower input resistance, higher resonance frequency, and higher resonance strength than COM neurons at all these voltages. The dynamic responses of $\mathrm{CPn}$ neurons were voltage dependent. Both resonance frequency (Fig. $5 C$ ) and resonance strength $(Q:-80 \mathrm{mV}, 1.07 \pm 0.02 ;-75 \mathrm{mV}, 1.06 \pm 0.03$; $-70 \mathrm{mV}, 1.14 \pm 0.03 ;-65 \mathrm{mV}, 1.08 \pm 0.01 ;-60 \mathrm{mV}, 1.05 \pm$ 0.01 ) were lower at more depolarized potentials. COM neurons exhibited little or no resonance, even at the most hyperpolarized potentials. In both neuron types, input resistance was voltage dependent (Fig. 5E).

The combination of resonance, sag, $R_{\mathrm{N}}$, rebound slope, and temporal summation suggested that $\mathrm{h}$-currents might contribute differently to the subthreshold properties of $\mathrm{CPn}$ and $\mathrm{COM}$ neurons. To test this, we recorded from $\mathrm{CPn}$ and COM neurons and bath applied the h-channel blocker ZD7288 (4-ethylphenylamino-1,2-dimethyl-6-methylaminopyrimidinium chloride) (20 $\mu \mathrm{M})($ Fig. $5 A-F)$. Both CPn and COM neurons were significantly hyperpolarized from their resting membrane potential in ZD7288 (Fig. 5G) $(p<0.01$; CPn, $n=8$; COM, $n=7)$. The functional membrane time constant of both $\mathrm{CPn}$ and COM neurons from $-65 \mathrm{mV}$ were significantly increased by ZD7288 (Fig. $5 F)(p<0.01 ; \mathrm{CPn}, n=8 ; \mathrm{COM}, n=7)$. Furthermore, both CPn and COM neurons exhibited higher $R_{\mathrm{N}}$ across membrane voltages with ZD7288 (Fig. $5 E)(p<0.01 ; \mathrm{CPn}, n=8$; COM, $n=7$ ), suggesting that h-currents contributed to the steady-state properties of both neuron types. Similar results were obtained with 

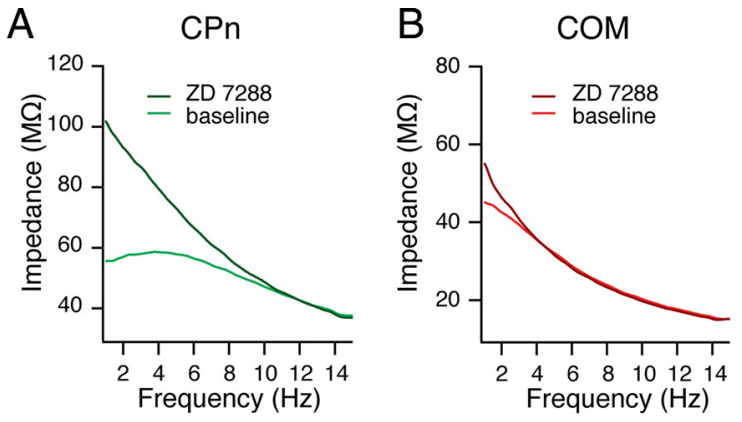

C

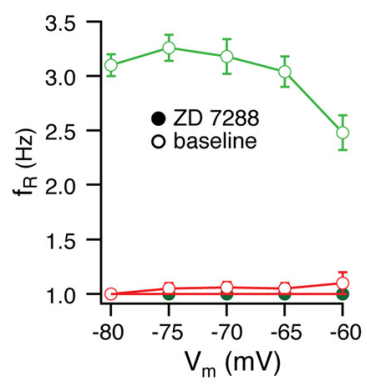

D

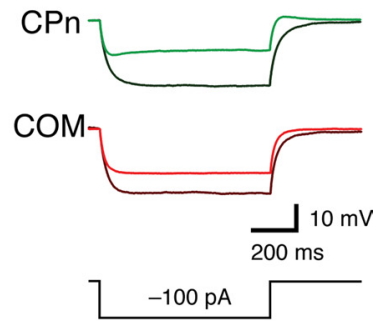

$\mathrm{E}$

$\mathrm{F}$
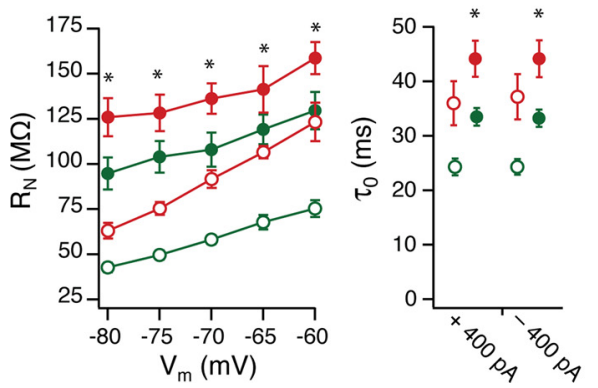

G

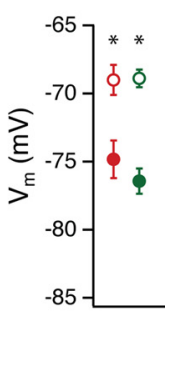

Figure 5. Differences in h-conductance contribute to distinct dynamic and steady-state properties. $\boldsymbol{A}, \boldsymbol{B}, \mathrm{COM}$ (red) and $\mathrm{CPn}$ (green) neurons were given $15 \mathrm{~s}, 15 \mathrm{~Hz}$ chirp stimuli across a range of membrane potentials $(\boldsymbol{C} ;-80$ to $-60 \mathrm{mV})$ before and after bath application of 20 $\mu \mathrm{M}$ ZD7288, eliminating membrane resonance in CPn neurons. Representative ZAPs at -70 $\mathrm{mV}$. $\boldsymbol{A}, \boldsymbol{B}$, Steady-state properties were affected in both groups. $\boldsymbol{D}$, Representative traces of a single current step (-100 pA) in (Pn (green) and COM (red) neurons before and after the addition of ZD7288 (black). $\boldsymbol{E}$, Input resistance measured as the slope of the linear fit from a family of current injections in CPn (green) and COM (red) neurons before (open circles) and after (filled circles) the addition of ZD7288. F, G, ZD7288 (filled circles) changes both the functional membrane time constant at $-65 \mathrm{mV}(\boldsymbol{F})$ and the resting membrane potential $(\boldsymbol{G})$ in both CPn (green) and COM (red) neurons. ${ }^{*} p<0.05$.

CPn neurons when slices were preincubated with $50 \mu \mathrm{M}$ ZD7288 and subsequently recorded from with $20 \mu \mathrm{M}$ ZD7288 in the pipette $(n=7)$. Blocking h-currents abolished differences in the dynamic responses of CPn and COM neurons. In ZD7288, resonance in $\mathrm{CPn}$ was abolished across all membrane potentials (Fig. $5 C)\left(-80\right.$ to $\left.-60 \mathrm{mV} ; f_{\mathrm{R}}=1.0 ; Q=1.0\right)$. Thus, it appears that the distinct static and dynamic properties of CPn and COM neurons may be attributable (at least) to differences in their h-currents.

In addition to resonance caused by the h-current, neurons can also exhibit resonance at more depolarized membrane potentials driven by the m-current (Hu et al., 2002, 2007, 2009). The rationale for these experiments was to establish whether m-current or h-current contributes to the resonance observed near resting membrane. These experiments were intended to address which currents contribute to resonance at rest, not the differences between cell types. As such, they were performed on unlabeled
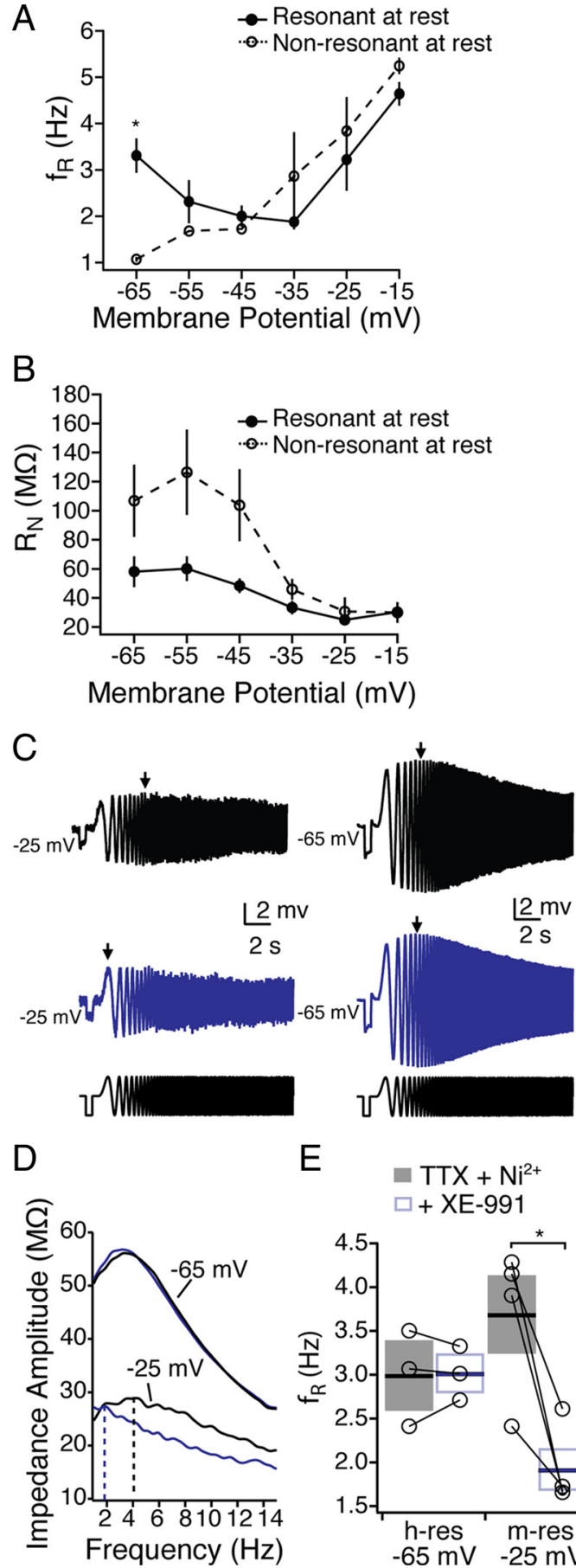

Figure 6. m-resonance in $\mathrm{mPFC}$ neurons. In the presence of $\mathrm{TTX}_{\mathrm{X}}$ and $\mathrm{Ni}^{2+}, \mathrm{mPFC}$ neurons were segregated into resonant and nonresonant depending on their resonance at $-65 \mathrm{mV}$. $\boldsymbol{A}, \boldsymbol{B}$, Resonance frequency $(\boldsymbol{A})$ and input resistance $(\boldsymbol{B})$ from resonant and nonresonant neurons from -65 to $-25 \mathrm{mV}$. $\boldsymbol{C}-\boldsymbol{E}$, The m-channel blocker XE991 (10 $\mu \mathrm{m})$ blocked resonance at -25 $\mathrm{mV}$, whereas resonance at $-65 \mathrm{mV}$ was unaffected. ${ }^{*} p<0.05$.

neurons. To test whether mPFC neurons generally exhibited $\mathrm{m}$-resonance, we injected chirp stimuli at more depolarized voltage potentials $(-60$ to $-15 \mathrm{mV})$ in the presence of sodium and calcium channel blockers (TTX, $0.001 \mathrm{~mm} ; \mathrm{Ni}^{2+}, 3 \mathrm{~mm}$ ) in unlabeled neurons (Fig. 6). In contrast to some previous work in hippocampus (Hu et al., 2002, 2009), we did not observe much resonance until very depolarized potentials (more than -35 $\mathrm{mV}$ ). All mPFC neurons exhibited m-resonance at very depolarized membrane potentials $\left(\right.$ at $-35 \mathrm{mV}: f_{\mathrm{R}}=2.87 \pm 0.95 \mathrm{~Hz} ; \mathrm{Q}=$ 


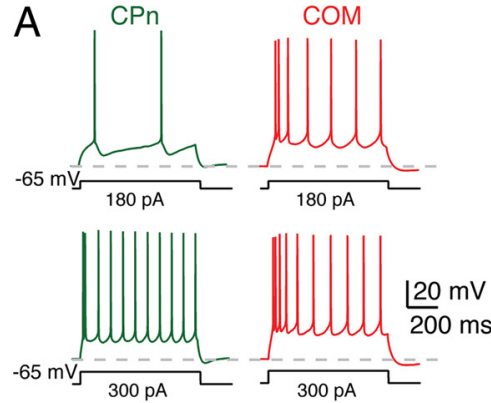

D

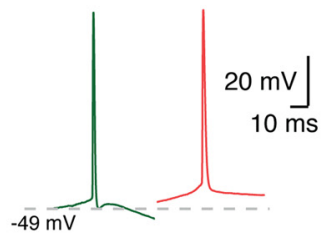

$\mathrm{H}$

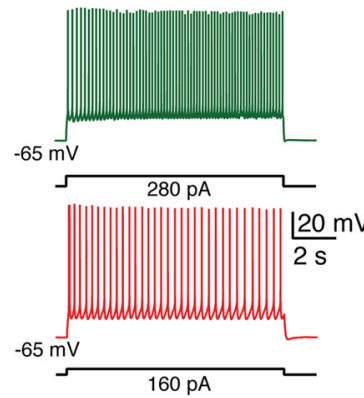

E

I
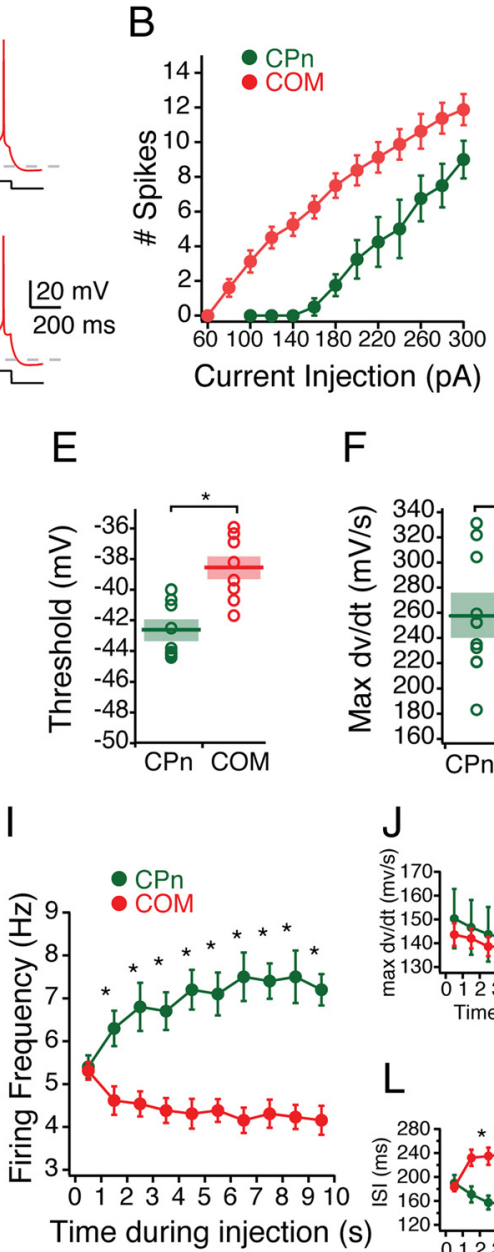

$\mathrm{F}$
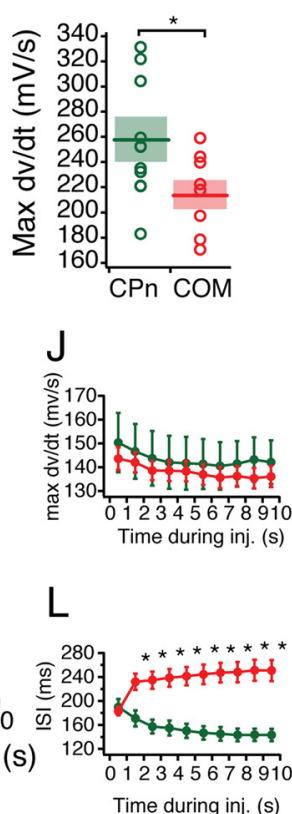

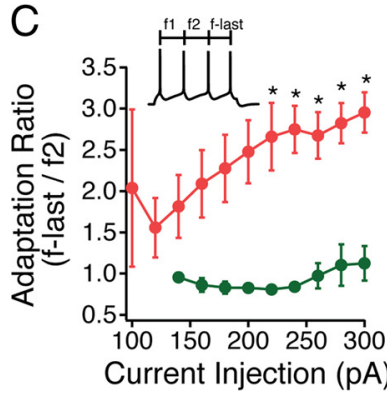

G

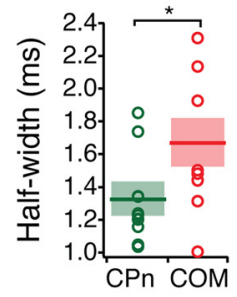

K

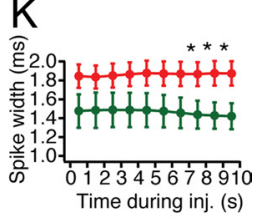

$M$

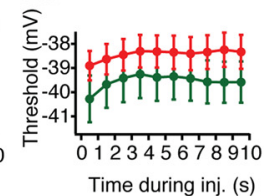

Figure 7. Active properties of COM versus CPn neurons. $A$, Representative responses of COM (red) and CPn neuron responses to $750 \mathrm{~ms}$ step depolarizations of 180 and $300 \mathrm{pA}$. B, Firing frequency of spikes elicited across a range of current injections ( $60-300 \mathrm{pA})$. C, Ratio of the first ISI to the last ISI. D, Representative traces of the first action potential in COM and CPn neurons with sufficient current to trigger four action potentials in $750 \mathrm{~ms}$. Action potentials in (Pn neurons were typically followed by a fast afterhyperpolarization and fast ADP. E-G, Threshold, rate of rise (max dv/dt), and AP half-widths of $\mathrm{COM}$ and $\mathrm{CPn}$ neurons. $\boldsymbol{H}$, COM neurons exhibit spike frequency adaptation, whereas $\mathrm{CPn}$ neurons exhibit spike acceleration. Representative traces of a $10 \mathrm{~s}$ current injection that elicits $5 \mathrm{~Hz}$ firing frequency in the first second. $I-M$, Changes in firing frequency, max $d v / d t$, interspike interval, spike width, and threshold over the course of a $10 \mathrm{~s}$ current injection. ${ }^{*} p<0.05$.

$1.10 \pm 0.04)$ regardless of whether they were resonant at $-65 \mathrm{mV}$ (Fig. 6A) (Kruskal-Wallis with Dunn's multiple comparisons test, $p<0.05$ at $-65 \mathrm{mV}, p>0.05$ at all other potentials). We then tested whether the m-current blocker XE991 [10,10-bis(4pyridinylmethyl)-9(10H)-anthracenone] affected resonance near the resting membrane potential, as well as at depolarized potentials $(-25 \mathrm{mV})$. The addition of the m-current blocker XE991 selectively reduced the $f_{\mathrm{R}}$ at a depolarized potential (Fig. 6C,D) $(-25 \mathrm{mV} ; n=4 ; p<0.05)$ but not hyperpolarized potentials $(n=3)$. This further suggested that the distinct subthreshold dynamic properties of CPn and COM neurons are the result of differences in the h-current.

\section{CPn and COM neurons express unique firing properties}

Having established the projection-specific subthreshold dynamic and integrative properties of CPn and COM neurons, we examined whether the neuron types were also distinct in their firing properties. To test this, we adjusted holding current such that the membrane potential was $-65 \mathrm{mV}$ and injected a range of depolarizing currents (60-300 pA in $20 \mathrm{pA}$ increments) for $750 \mathrm{~ms}$. As expected given their higher input resistance, COM neurons required less current to be driven to fire action potentials (Fig.
$7 A, B, H)$. The minimum amount of current necessary to elicit an action potential with a $750 \mathrm{~ms}$ current injection in COM neurons was $96 \pm 7 \mathrm{pA}(n=8)$, whereas the minimum amount in CPn neurons was $191 \pm 20 \mathrm{pA}(n=7)$.

$\mathrm{CPn}$ and COM neurons were distinct in several AP characteristics (Fig. 7D-G). CPn neurons exhibited a more hyperpolarized AP threshold $(\mathrm{CPn},-42.66 \pm 0.58 \mathrm{mV}$; COM, $-38.58 \pm 1.99$ $\mathrm{mV}$; Student's $t$ test, $p<0.05)$, faster rate of rise ( $\max d v / d t \mathrm{CPn}$, $255.77 \pm 12.00 \mathrm{mV} / \mathrm{ms}$; COM, $214.12 \pm 13.27 \mathrm{mV} / \mathrm{ms} ; p<0.05)$ and shorter AP half-width $(\mathrm{CPn}, 1.31 \pm 0.26 \mathrm{~ms}$; COM, $1.67 \pm$ $0.42 \mathrm{~ms}$; Student's $t$ test, $p<0.05$ ). Application of ZD7288 did not affect any of the action potential parameters measured (data not shown).

Neurons in other cortical regions have distinct firing patterns depending on their projection targets (Wang and McCormick, 1993; Morishima and Kawaguchi, 2006; Otsuka and Kawaguchi, 2008). This was also the case for CPn and COM neurons in mPFC. Although COM neurons fired action potentials more readily, they displayed spike adaptation that increased with greater current injections (Fig. 7C). Both CPn and COM neurons could fire a doublet [interspike interval (ISI) $<15 \mathrm{~ms}$ ] with sufficient current injection. However, in CPn neurons, the ISI fol- 
lowing this doublet was longer, whereas in COM neurons the ISIs progressively increased (Fig. 7C). To examine spike adaptation and acceleration more carefully, we injected current that resulted in four action potentials over $750 \mathrm{~ms}(\mathrm{CPn}, 209 \pm 22 \mathrm{pA}$; COM, $124 \pm 7 \mathrm{pA}$ ) for an extended duration (10 s) (Fig. $7 \mathrm{H}$ ). Although both neuron types initially fired at the same rate $(5.3 \mathrm{~Hz}), \mathrm{CPn}$ neurons progressively increased in firing frequency over time, whereas COM neurons accommodated, firing slightly less (4.0 $\mathrm{Hz}$ ). The acceleration in CPn neuron output occurred with no significant change in max $d v / d t$, action potential threshold, or spike widths (Fig. 7J-M).

\section{Noradrenergic modulation of prefrontal cortical neurons depends on their projection targets}

Noradrenergic modulation of mPFC neurons through $\alpha 2 \mathrm{~A}$ receptors enhances working memory in rodents and monkey, an effect occluded by reduction in the h-current (Wang et al., 2007). Several studies have demonstrated that bath application of the $\alpha 2$ receptor agonist clonidine modulates the intrinsic properties of layer V mPFC neurons (Carr et al., 2007; Barth et al., 2008). Given the different contributions of h-current to COM versus CPn neurons (Figs. 4, 5), we sought to examine whether the effects of adrenergic modulation on $\mathrm{mPFC}$ neurons depended on their long-range projection targets.

Adrenergic modulation of subthreshold properties was greater in CPn neurons than COM neurons. Clonidine $(100 \mu \mathrm{M})$ caused both COM and CPn neurons to hyperpolarize, but the effect on CPn neurons was significantly larger (COM, $-2.51 \pm$ $0.33 \mathrm{mV}, n=5$, paired Student's $t$ test, $p<0.05$; CPn, $-6.37 \pm$ $0.79 \mathrm{mV}, n=5$, paired Student's $t$ test, $p<0.05)$. With this hyperpolarization, both neurons displayed a small but significant increase in $R_{\mathrm{N}}$ (COM, $9.1 \pm 2.2 \%, n=5$, paired Student's $t$ test, $p<0.05$; CPn, $5.6 \pm 2.0 \%, n=5$, paired Student's $t$ test, $p<$ $0.05)$. When compared at the same membrane potential (Fig. 8), both neuron types increased in input resistance (Fig. $8 A, B)(n=$ 5 , Student's paired $t$ test, $p<0.05$ ). Notably, CPn neurons increased significantly more than COM neurons (Fig. $8 C$ ) (CPn, $39.08 \pm 7.17 \%$; COM, $17.57 \pm 4.96 \%$; Student's $t$ test, $p<0.05)$. The sag ratio of CPn neurons (but not COM neurons) was significantly reduced (Fig. $8 D$ ). Interestingly, the subset of COM neurons (two of five) that expressed some sag $(>5 \%)$ were reduced in sag ratio. Adrenergic modulation significantly increased the functional membrane time constant of CPn neurons (Fig. $8 E-G$ ) (repeated-measures ANOVA, $F=21.741$, Bonferroni's multiple comparisons; $n=6 ; p<0.001$ ). In COM neurons, the functional membrane time constant was not significantly affected ( $n=5$; repeated-measures ANOVA, $F=2.974, p=0.07$ ), although the time constant from hyperpolarizing pulses did increase somewhat $(7.9 \pm 5.6 \% ; n=5)$.

Adrenergic modulation altered the dynamic properties of $\mathrm{CPn}$ but not COM neurons. In the presence of clonidine, $\mathrm{CPn}$ neurons became nonresonant $\left(f_{\mathrm{R}}, 3.7 \pm 0.3\right.$ to $1.0 \mathrm{~Hz} ; \mathrm{Q}, 1.15 \pm$ 0.02 to $1.02 \pm 0.01$; both $n=5$; Student's paired $t$ test, $p<0.05$ ), making them not significantly different from COM neurons (Fig. $8 H, I)$. No effect of clonidine was observed on the impedance profiles of COM neurons. Summation of $\alpha$ EPSPs was drastically increased in CPn but not COM neurons (Fig. $8 \mathrm{~J}, \mathrm{~K}$ ). In the presence of clonidine, current injections that previously produced a $10 \mathrm{mV}$ depolarization in CPn neurons now summated sufficiently to trigger an action potential $(n=4)$. In contrast in COM neurons, a much smaller increase in $\alpha$ EPSP occurred, never with an action potential $(n=5)$. To compare changes in summation, we reduced the initial current amplitude to produce an equiva- lent $10 \mathrm{mV}$ depolarization. Under these conditions, temporal summation in CPn neurons increased $(21.91 \pm 4.17 \% ; n=5$; paired Student's $t$ test, $p<0.01$ ). Although temporal summation in COM neurons did increase slightly, this increase was not significant $(5.26 \pm 2.00 \%$ increase; $n=5$; paired Student's $t$ test, $p=$ 0.058 ) and was significantly less than CPn neurons (Student's $t$ test, $p<0.01)$.

Because adrenergic modulation increased the likelihood of summed $\alpha$ EPSPs producing an action potential, we further examined the effect of clonidine on neuronal excitability. To test this, we examined whether clonidine also increased the number of action potentials from a step current depolarization (Fig. 9). In response to the same current depolarization that had triggered four action potentials before clonidine, both neurons fired significantly more action potentials, although the effect in CPn neurons was greater (COM, $6.4 \pm 0.24$ spikes, $n=5$, Student's paired $t$ test, $p<0.05$; CPn, $9.4 \pm 0.68$ spikes, $n=5$, Student's paired $t$ test, $p<0.05)$. AP threshold was decreased in both neuron types (Fig. 9C) $(\mathrm{CPn},-2.69 \pm 0.23 \mathrm{mV}$; COM, $-3.99 \pm 0.16 \mathrm{mV}$; Student's paired $t$ test, $p<0.05$ ). The AP amplitude (threshold to peak) was reduced in CPn neurons but not COM neurons (Fig. 9D) (Student's paired $t$ test, $p<0.05$ ). The AP rate of rise and the AP half-width were not significantly changed (Fig. 9E,F). The number of action potentials elicited with depolarization increased in clonidine for both neuron types, with shorter ISIs (Fig. 9G). After the initial ISI, CPn neurons continued to exhibit a small decrease in the ISI, whereas COM neurons did not.

\section{Cholinergic modulation of prefrontal cortical neurons depends on their projection targets}

Increases in acetylcholine occur in the PFC during cue detection and working memory-like tasks (Parikh et al., 2007). Similar to the activation of $\alpha 2$-adrenergic receptors, modulation via muscarinic receptors in PFC enhances working memory task performance (Herremans et al., 1997; Wall et al., 2001; Chudasama et al., 2004). The mechanism(s) underlying this enhancement remain unclear. One possible target may be the h-current, because muscarinic modulation reduces the dynamic response of entorhinal grid cells (Heys et al., 2010). Therefore, we tested whether the subthreshold properties of $\mathrm{MPFC}$ neurons are modulated by acetylcholine as well.

First, we examined changes in the intrinsic properties with bath application of carbachol (CCh) $(20 \mu \mathrm{M})$. During wash-in of $\mathrm{CCh}$, both neuron types showed a transient decrease in steadystate input resistance (measured from a single hyperpolarizing 50 pA step: COM, $-15.15 \pm 3.73 \%, n=9$, Student's paired $t$ test, $p<0.05 ; \mathrm{CPn},-28.89 \pm 3.68 \%, n=12$, Student's paired $t$ test, $p<0.01)$. In conjunction with this decrease in input resistance, both neuron types hyperpolarized slightly, although in COM neurons this was not significant (COM, $-2.17 \mathrm{mV} \pm 1.05 \mathrm{mV}$, $n=9$, Student's paired $t$ test, $p<0.05 ; \mathrm{CPn},-3.15 \pm 0.71 \mathrm{mV}$, $n=12$, Student's paired $t$ test, $p=0.07$ ). Within minutes after this hyperpolarization and decrease in $R_{\mathrm{N}}$, both neurons depolarized such that there was no significant difference in the resting membrane potential compared with control conditions (COM, $-0.15 \pm 1.22 \mathrm{mV}, n=9, p=0.91$, Student's paired $t$ test; CPn, $+1.25 \pm 0.67, n=12, p=0.09$, Student's paired $t$ test).

After the transient effect of CCh subsided, cholinergic modulation did not consistently modify the steady-state properties of either neuron type (Fig. 10). Both $R_{\mathrm{N}}$ (as measured from a family of current injections) and the effective membrane time constant measured at $-65 \mathrm{mV}$ were not significantly different from control (Fig. 10A-D) (CPn, $n=7, p=0.52 ; \mathrm{COM}, n=11, p=0.54$, 
Student's paired $t$ test). Although the steady-state properties of the neurons were unchanged, there was a small but significant change in the response of $\mathrm{CPn}$ neurons to dynamic stimuli with cholinergic modulation (Fig. 10). With CCh, the voltage sag in response to hyperpolarizing steps was significantly reduced (Fig. 10C) (pre, $16.3 \pm 0.3 \%$; in CCh, $12.6 \pm 0.2 \%$; $n=7$; Student's $t$ test, $p<0.01$ ). Similarly, there was a small but significant reduction in the resonance frequency and resonance strength in the presence of $\mathrm{CCh}$ (Fig. $10 E, F)(Q$ at $-65 \mathrm{mV}, 1.13 \pm 0.03$ to $1.06 \pm 0.02 ; n=10$; Student's paired $t$ test, $p<0.05)$. This shift in the resonance frequency reversed with washout of $\mathrm{CCh}$ (Fig. 10G) $(n=6)$ and was blocked by the muscarinic antagonist pirenzepine (data not shown $(n=3)$. Next, we tested the effects of CCh on resonance and steadystate input resistance from -85 to -60 $\mathrm{mV}$ in both neuron types (Fig. $10 \mathrm{H}-\mathrm{J}$ ). Across a range of membrane potentials, steady-state input resistance increased slightly in both neuron types, but this change was not significant. In COM neurons, we observed no change in the resonance frequency, whereas in CPn neurons, CCh changed resonance in a voltagedependent manner. Significant reductions in $f_{\mathrm{R}}$ (Fig. 10I) occurred at -60 through $-75 \mathrm{mV}$ but not at more hyperpolarized potentials. Similarly, CCh-induced changes in resonance strength occurred only from -70 to $-65 \mathrm{mV}$. Together, these data suggested that CCh induced a subtle shift in the dynamic but not the steady-state responses of CPn neurons.

\section{Activity-dependent intrinsic persistent firing in layer $\mathrm{V}$ neurons is projection-target dependent}

Cholinergic modulation altered the subthreshold dynamic responses of CPn but not COM neurons (Fig. 10). Next, we sought to determine whether cholinergic modulation altered the response of the neurons to suprathreshold stimulation. Cholinergic modulation enables neurons in PFC and other brain regions to fire persistently in response to transient suprathreshold stimulation (Andrade, 1991; Haj-Dahmane and Andrade, 1996, 1998, 1999; Egorov et al., 2002, 2006; Fransén et al., 2006; Gulledge et al., 2009; Zhang and Seguela, 2010). In many cases, this persistent activity is hypothesized to occur independent of network reverberations because it is sustained in the present of synaptic blockers. Such single-neuron persistent activity has been proposed to increase the robustness of the mnemonic
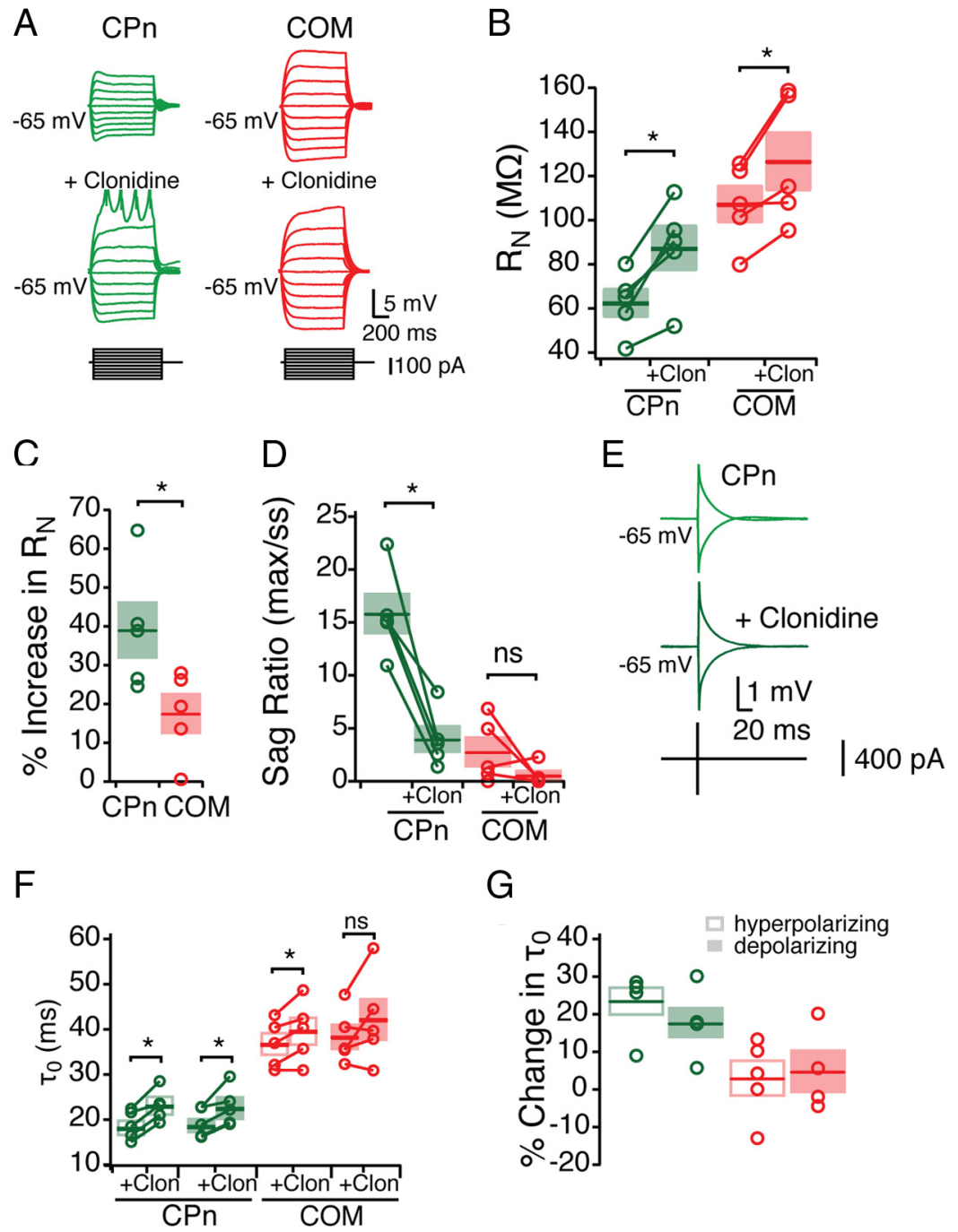

$\mathrm{G}$

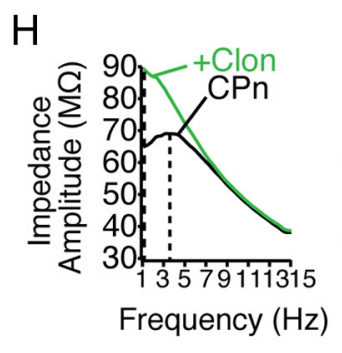

$\mathrm{J}$

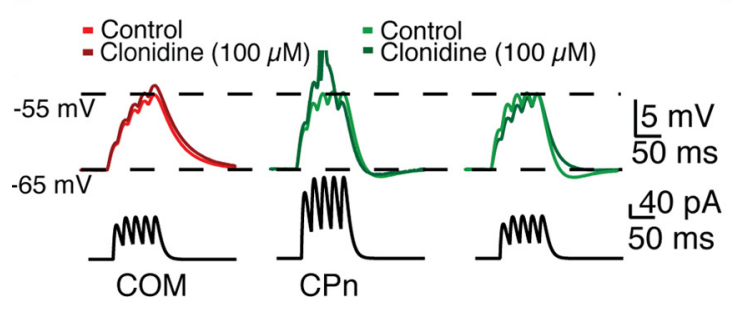

।

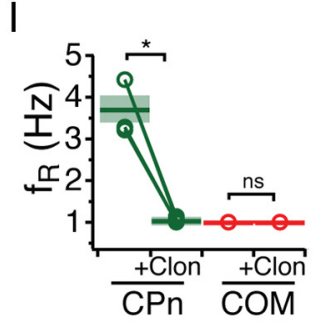

$\mathrm{K}$

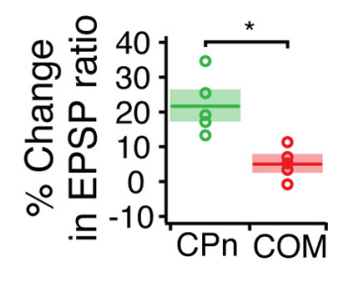

Figure 8. Noradrenergic modulation of subthreshold properties of mPFC neurons. Bath application of the $\alpha 2$-adrenergic agonist clonidine (Clon; $100 \mu \mathrm{M}$ ) differentially effects CPn and COM neurons. $\boldsymbol{A}-\boldsymbol{G}$, Effects of clonidine on steady-state input resistance $(\boldsymbol{A}-\boldsymbol{C})$, sag ratio $(\boldsymbol{D})$, and membrane time constant $(\boldsymbol{E}-\boldsymbol{G}) . \boldsymbol{H}, \boldsymbol{I}$, Clonidine shifts the ZAP of CPn but not COM neurons, making CPn neurons drop in resonance frequency. $J, \alpha$ EPSPs were injected with current such that they depolarized the neurons from -65 to $-55 \mathrm{mV}$. With the addition of clonidine, only CPn neurons are driven to fire an action potential. $\boldsymbol{K}$, Reducing the current injection to span from -65 to $-55 \mathrm{mV}$ in the presence of clonidine reveals an increase in CPn but not COM EPSP ratio. ${ }^{*} p<0.05$. 

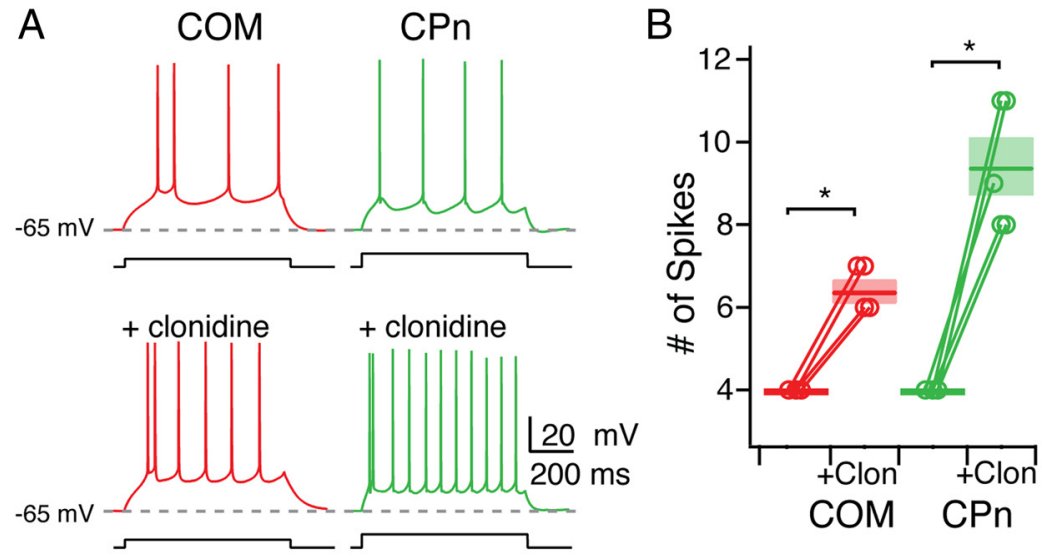

C

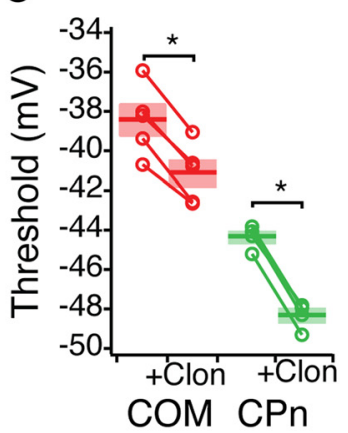

D

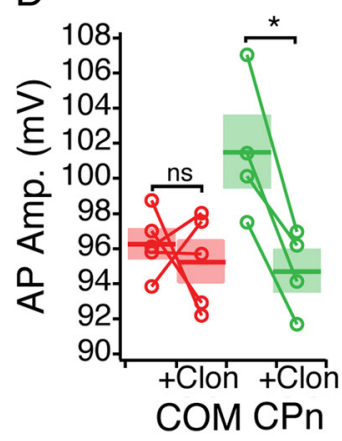

E

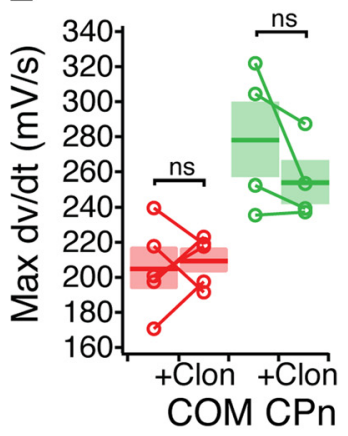

F

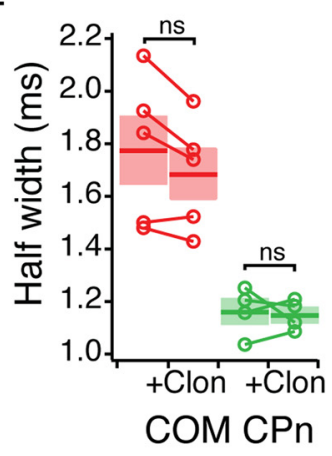

G

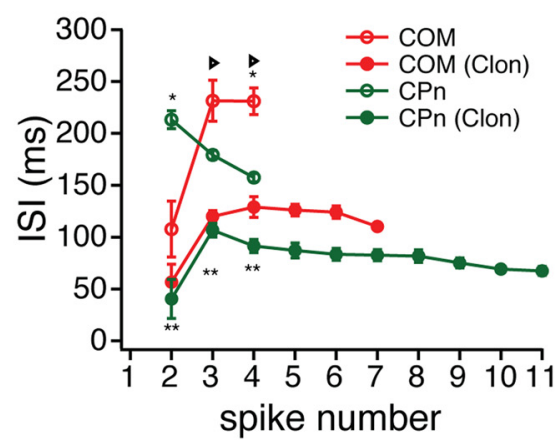

Figure 9. Noradrenergic modulation of the excitability of mPFC neurons. $\boldsymbol{A}$, Representative traces of the effect of clonidine (100 $\mu \mathrm{M})$ on the excitability of $\mathrm{COM}$ (Red) and $\mathrm{CPn}$ (green) neurons. $\boldsymbol{B}$, Group data showing the increase in the number of spikes elicited in COM and CPn neurons before and after the addition of clonidine (Clon). $\mathbf{C}-\boldsymbol{F}$, Changes in spike parameters caused by clonidine in COM and CPn neurons. G, Changes in the interspike interval of both COM and CPn neurons. ${ }^{*} p<0.05$ (significant difference between COM and (PN in control conditions); ${ }^{* *} p<0.05$ (significant difference between (Pn control and (Pn clonidine); triangle, $p<0.05$ (significant difference between COM control and COM clonidine).

activity underlying working memory (Wang, 2001). However, whether cholinergic modulation enables neurons to display this activity-dependent single-neuron persistent firing depends on their long-range projection targets remains uncharacterized.

To test whether mPFC neurons were capable of single-cell persistent activity, we injected the amount of current sufficient to trigger four action potentials in $750 \mathrm{~ms}$ for an extended duration (10 s; $n=24)$. In the absence of modulators, both COM and CPn neurons were quiescent after removal of the current injection, even when two times $(n=19)$ and three times $(n=14)$ this depolarizing current was injected (Fig. $11 A, B$ ). In the presence of the $\mathrm{CCh}$, however, $\mathrm{CPn}$ neurons became persistently active beyond the depolarizing current injection (Fig. $11 \mathrm{~B}$ ). This persistent activity could be reversed with a large hyperpolarizing current injection and triggered repeatedly with subsequent depolarization (data not shown). The ability to fire persistently depended on the projection target of the neuron. Although 8 of $11 \mathrm{CPn}$ neurons fired persistently ( $\geq 30 \mathrm{~s}$ ) (Fig. $11 \mathrm{~A}$ ), only 3 of 13 COM neurons fired persistently (Fig. 11B). Some COM neurons did elicit a few action (for $<5 \mathrm{~s}$ ) potentials the first time tested (4 of 13) (data not shown), but in most cases, COM neurons became quiescent at the end of the current injection (6 of 13). Neurons that failed to fire persistently could not do so even with two $(n=12)$ and three $(n=10)$ times the amount of depolarizing current.

What differences between CPn and COM neurons may explain why CPn neurons were more likely to fire persistently? Unlike clonidine, CCh did not alter the input resistance of CPn or COM neurons. Several suprathreshold properties were distinct between COM and CPn neurons (Fig. 7E-G). Thus, we examined whether suprathreshold properties may account for the propensity to fire persistently. During the depolarizing current injections, CCh increased the firing frequency of both COM and CPn neurons (twofactor ANOVA with repeated measures; $\mathrm{CPn}, F_{(1,7)}=12.339, p<0.01$; COM, $\left.F_{(1,11)}=12.17, p<0.01\right)($ Fig. $11 D)$. The total number of action potentials elicited was significantly enhanced by $\mathrm{CCh}$ in both CPn and COM neurons and was significantly greater in CPn neurons (twofactor ANOVA with repeated measures; CCh effect, $F_{(1,20)}=42.54, p<0.001$; cell type, $F_{(1,18)}=7.41, p<0.05 ; \mathrm{CCh} \times$ cell type, $\left.F_{(1,18)}=14.96, p<0.005\right)$. However, the greater number of action potentials elicited in CPn neurons was unlikely to account for their ability to persistently fire because COM neurons failed to fire persistently even with larger depolarizing current injections (Fig. 11A).

As was the case in the absence of modulators, long current injections in CPn but not COM neurons produced an acceleration in firing frequency over time (two-factor ANOVA with repeated measures; CPn, $F_{(9,63)}=5.16, p<0.05$; COM, $F_{(9,99)}=0.56, p=0.82$ ) (Fig. $11 D)$. Furthermore, spikes in COM neurons were attenuated in amplitude and rate of rise with CCh. Although CCh increased the excitability of both COM and CPn neurons, changes in several AP parameters suggested a decrease in the ability of the neurons to elicit spikes (Fig. $11 E-H$ ). In both CPn and COM neurons, the AP threshold increased (CPn, $F_{(1,7)}=22.108, p<0.005$; COM, $\left.F_{(1,11)}=5.94, p<0.05\right)$ (Fig. $11 E$ ), the AP rate of rise decreased $\left(\mathrm{CPn}, F_{(1,7)}=31.24, p<0.001 ; \mathrm{COM}, F_{(1,11)}=19.89, p<0.001\right)$ (Fig. $11 F)$, the AP amplitude decreased (CPn, $F_{(1,7)}=6.57, p<$ 0.05; COM, $\left.F_{(1,11)}=30.17, p<0.001\right)($ Fig. $11 H)$, and the AP width increased $\left(\mathrm{CPn}, F_{(1,7)}=44.49, p<0.001\right.$; COM, $F_{(1,11)}=$ 26.35, $p<0.001$ ) (Fig. 11G). Together, these CCh-induced 
changes appeared unlikely to be responsible for the persistent activity. However, the effect of CCh on AP rate of rise, AP height, and AP width were all significantly greater in COM neurons than CPn neurons (two-factor mixed ANOVA; AP rate of rise, $F_{(1,18)}=10.81, p<0.005 ; \mathrm{AP}$ height, $F_{(1,18)}=30.36, p<0.001$; AP width, $\left.F_{(1,18)}=60.35, p<0.001\right)$. The fact that COM neurons become less likely to elicit spikes in CCh to a much greater degree than CPn neurons may account for why they are less likely to fire persistently during long current injections.

To test explicitly whether differences in propensity of CPn and COM neurons to fire were simply attributable due to changes in the active properties, we triggered persistent activity with a controlled number of action potentials. Brief (1 ms) depolarizing current injections (1-2 nA), each sufficient to trigger an action potential, were delivered at $20 \mathrm{~Hz}$. Similar to the long step depolarization, CPn neurons were more likely to fire persistently ( 7 of $11 \mathrm{CPn}$ vs 2 of 9 COM neurons). To further examine the tendency of different neurons to fire, we changed two parameters: the number of action potentials and the membrane potential. Depolarizing the membrane potential to $-60 \mathrm{mV}$ enhanced the likelihood of CPn neurons to fire persistently. Although at $-65 \mathrm{mV}$, five APs was sufficient to trigger persistent firing in only 1 of $11 \mathrm{CPn}$ neurons and 1 of 9 COM neurons, at $-60 \mathrm{mV}$, five APs triggered persistent activity in 5 of $11 \mathrm{CPn}$ and 0 of 9 COM neurons. Even in the absence of $\mathrm{CCh}$, one CPn neuron fired persistently (in response to five APs at -60 $\mathrm{mV})$. Changing the number of action potentials did not appear to increase the likelihood of persistently firing. Increasing the number of spikes only converted 1 of $11 \mathrm{CPn}$ and 1 of $9 \mathrm{COM}$ neurons to fire persistently, and these were only in conjunction with depolarizing the membrane potential to $-60 \mathrm{mV}$. All of the CPn neurons that fired persistently $(n=8)$ did so with multiple test injections. In contrast, only one COM neuron that fired persistently once did so with subsequent test injections ( 1 of 4 tested). In summary, CPn neurons still had a greater propensity to fire than COM neurons, even when the number of action potentials triggering persistently activity was the same.

Persistent activity is hypothesized to be driven by a calcium activated nonselective cation (CAN) current (Haj-Dahmane and Andrade, 1999; Egorov et al., 2002, 2006; Fransén et al., 2006; Zhang and Seguela, 2010). This CAN current, which is present in layer $\mathrm{V}$ pyramidal neurons in the PFC (Haj-Dahmane and Andrade, 1999), can be revealed by a brief
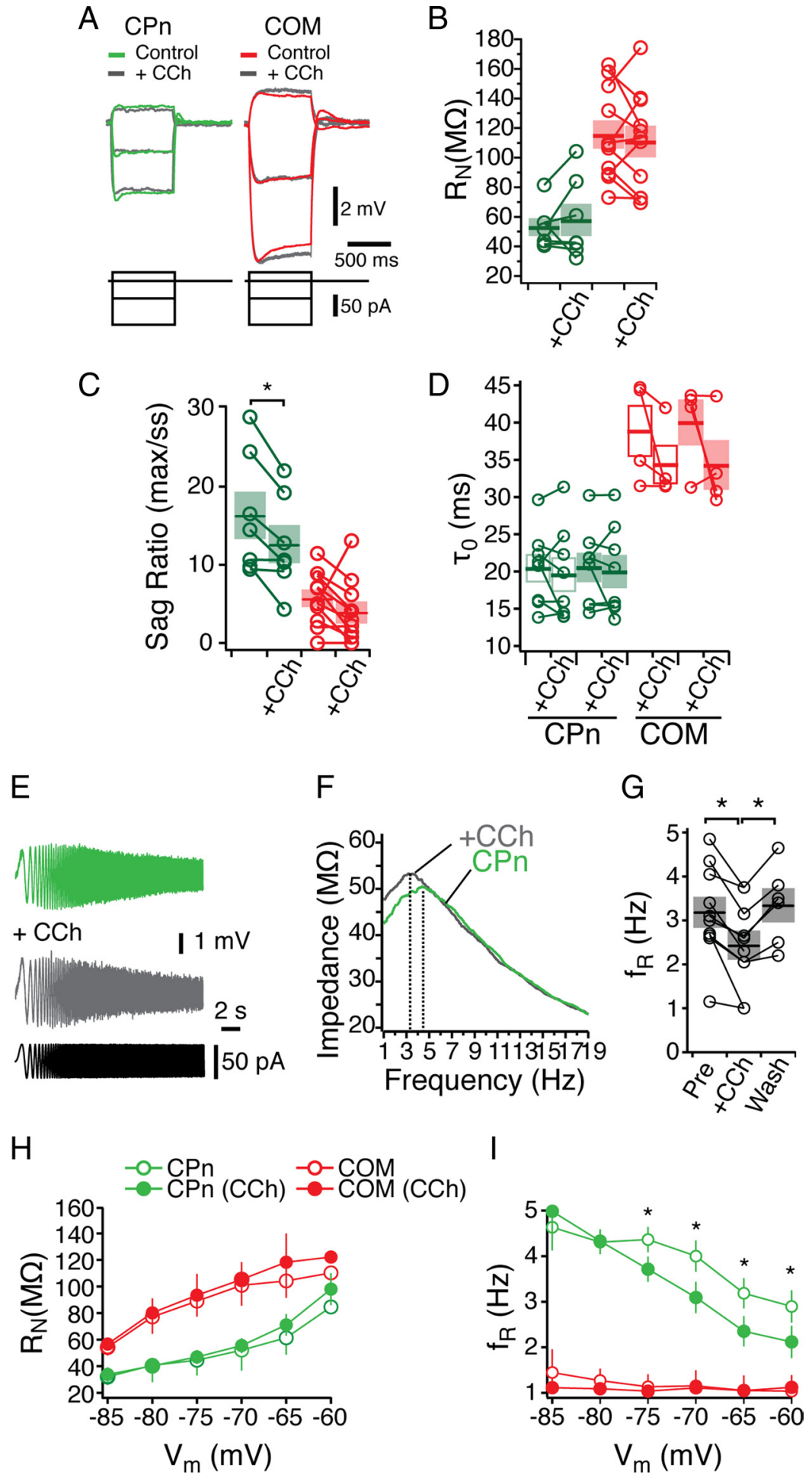

Figure 10. Cholinergic modulation of subthreshold properties in $\mathrm{MPFC}$ neurons. $\boldsymbol{A}$, Representative traces current injections in COM (red) and CPn (green) neurons. Overlays are with the addition of $20 \mu \mathrm{m}$ the cholinergic agonist CCh (gray). $\boldsymbol{B}$ - $\boldsymbol{D}$, Changes in steady-state input resistance $(\boldsymbol{B})$, sag ratio $(\boldsymbol{C})$, and membrane time constant $(\boldsymbol{D})$ elicited by $\mathbf{C C h}$. $\boldsymbol{E}-\boldsymbol{G}$, CCh reduced the resonance frequency of $C P n$ neurons in a reversible manner. $\boldsymbol{H}, \boldsymbol{I}$, Input resistance $(\boldsymbol{H})$ and resonance frequency $(\boldsymbol{I})$ before (open circles) and in the presence of $20 \mu \mathrm{M} C \mathrm{Ch}$ (filled circles) in both $\mathrm{COM}$ (red) and $\mathrm{CPn}$ (green) neurons at holding potentials from -85 to $-60 \mathrm{mV}$. ${ }^{*} p<0.05$. 
A

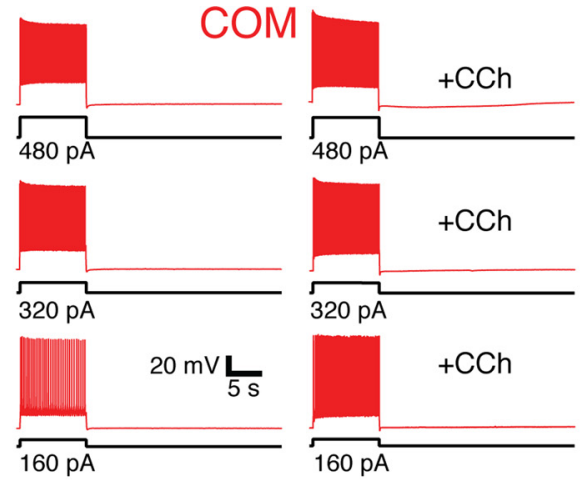

B
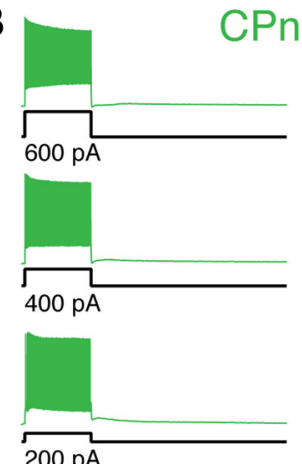

$\mathrm{D}$
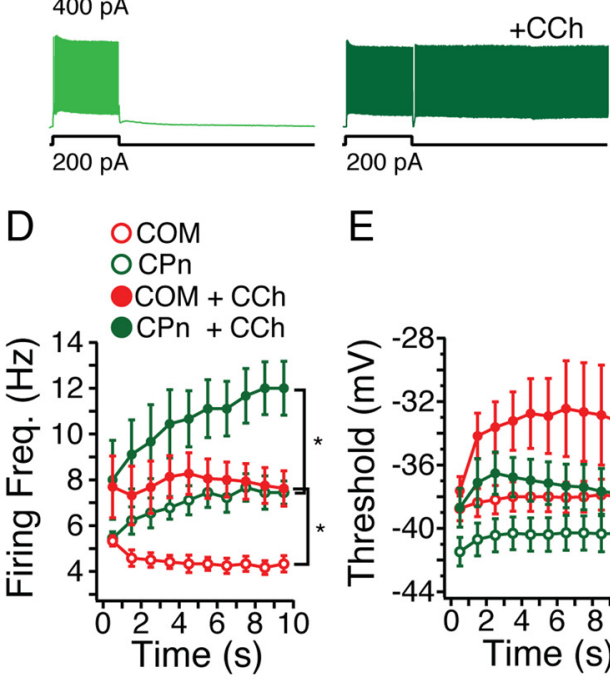

E

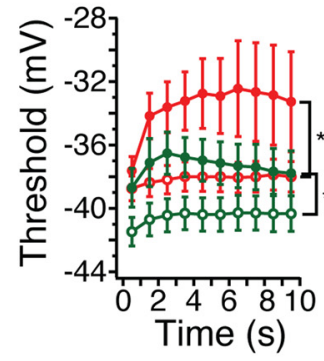

$\mathrm{G}$

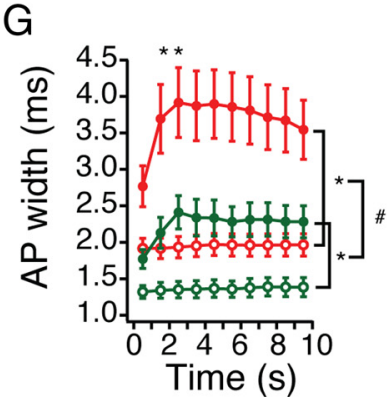

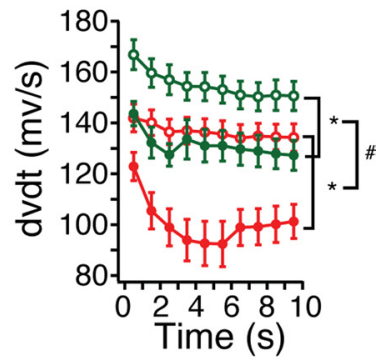

C

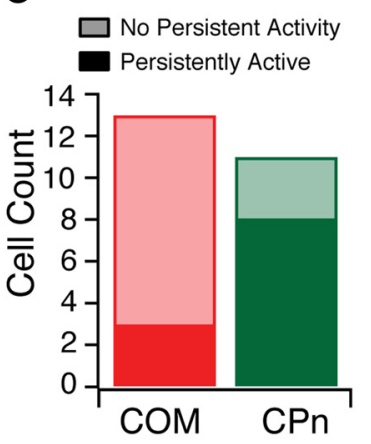

$\mathrm{F}$

$\mathrm{H}$

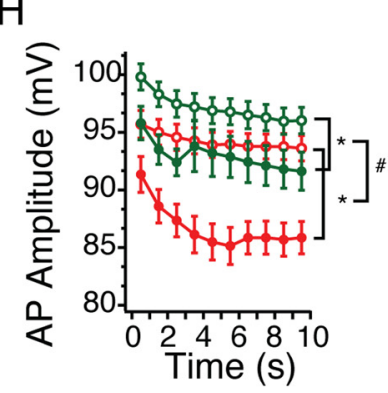

Figure 11. Projection dependence of single-neuron persistent activity in the presence of cholinergic modulation. $A, C O M$ neurons are depolarized for $10 \mathrm{~s}$ with one, two, and three times the amount of current sufficient to drive $5 \mathrm{~Hz}$ firing frequency for the initial second. With the addition of the cholinergic agonist $(C \mathrm{Ch}, 20 \mu \mathrm{m}), \mathrm{COM}$ neurons exhibit a slight afterdepolarizing potential but no persistent activity. $\boldsymbol{B},(\mathrm{CP}$ neurons depolarized in the same manner fire persistently only with the addition of $\mathrm{CCh}$ with one time the current injection. $C$, A greater proportion of $\mathrm{CPn}$ (green) neurons could be triggered to fire persistently in the presence of CCh by 10 s depolarization than COM neurons (red). D-I, Spiking characteristics of COM (red) and CPn (green) neurons before (open circles) and with the addition of $20 \mu \mathrm{m} \mathrm{CCh}$ (filled circles). ${ }^{*} p<0.05$ (significant difference between control and $\mathrm{CCh}$ condition); ${ }^{\#} p<0.05$ (significant difference in the effect of CCh on COM vs (Pn neurons).

$n=6)$. However, with the application of CCh, the size of the ADP was increased sixfold in CPn neurons but only slightly in most COM neurons (with CCh: COM, $2.75 \pm 1.24 \mathrm{mV}$; CPn, $5.98 \pm$ $1.05 \mathrm{mV}$ ). This modulation was specific for CCh and indepen- dent of h-channels, because the presence of clonidine or ZD7288 did not induce an ADP in either neuron type (data not shown), nor did clonidine trigger persistent activity ( 0 of $4 \mathrm{COM}$ neurons and 0 of $2 \mathrm{CPn}$ neurons) (data not shown).

\section{Discussion}

Here we show that, within rat $\mathrm{mPFC}$, there is considerable heterogeneity in the intrinsic properties of layer $\mathrm{V}$ pyramidal neurons in the absence of modulation. Neurons that project to the contralateral cortex (COM) are nonresonant and have a high input resistance, slow membrane time constant, and high temporal summation. Neurons that project subcortically to the pons $(\mathrm{CPn})$ resonate within the theta frequency range $(3-6 \mathrm{~Hz})$ and have a low input resistance, fast membrane time constant, and low temporal summation. h-current blockade with ZD7288 eliminates the distinct subthreshold properties of COM and CPn neurons. $\mathrm{COM}$ and $\mathrm{CPn}$ neurons also have unique suprathreshold properties independent of h-currents. As a result of their distinct intrinsic properties, adrenergic and cholinergic modulation does not affect $\mathrm{COM}$ and $\mathrm{CPn}$ neurons equally. Both muscarinic and $\alpha 2$-adrenergic modulation changed the dynamic properties of $\mathrm{CPn}$ but not $\mathrm{COM}$ neurons. Furthermore, in response to muscarinic modulation, $\mathrm{CPn}$ neurons had a much greater propensity toward single-cell persistent activity than COM neurons.

Pyramidal neurons with different long-range projection targets have been shown to have distinct morphology and physiology in several neocortical regions (Wang and McCormick, 1993; Kasper et al., 1994a,b; Christophe et al., 2005; Molnár and Cheung, 2006; Morishima and Kawaguchi, 2006; Hattox and Nelson, 2007; Le Bé et al., 2007; Otsuka and Kawaguchi, 2008; Brown and Hestrin, 2009). The findings of this study expand this pattern to the rostroventral rat mPFC, which is known to contribute to working memory-like tasks, pattern recognition, motor preparation, and fear acquisition/ extinction in these animals (Dalley et al., 2004; Burgos-Robles et al., 2007; Fujisawa et al., 2008).

Although differences in the firing properties or their interconnectivity have been the focus of previous studies of projection neurons, in mPFC their subthreshold intrinsic properties and responses to dynamic stimuli are distinct. COM neurons act as low-pass filters; they do not resonate in response to chirp stimuli (Figs. 2, 5). In contrast, CPn neurons act as bandpass filters; they resonate preferentially in the theta frequency range 

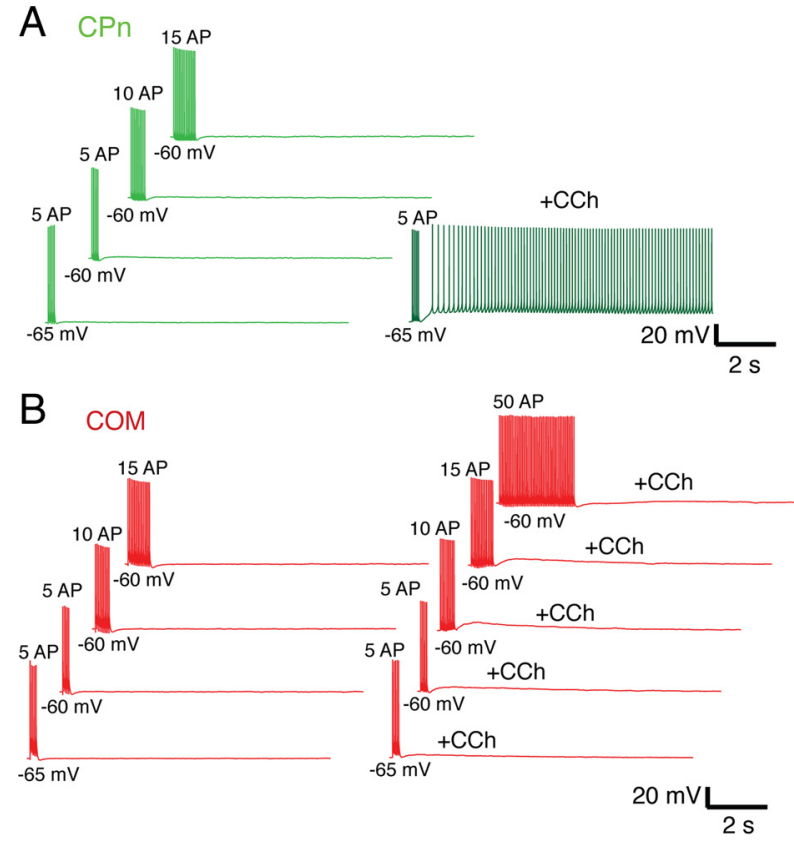

C
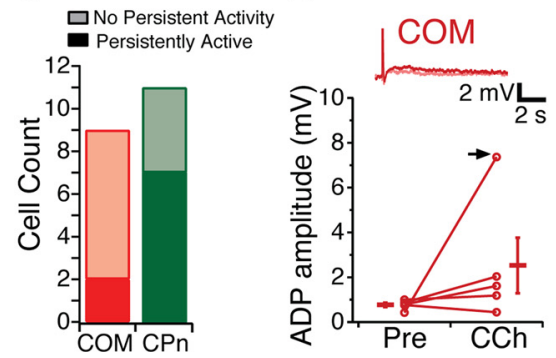

E

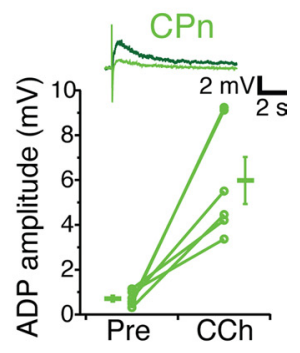

Figure 12. Subcortically projecting neurons can be driven to fire persistently with spike trains. $A, C P n$ neurons are driven to fire 5, 10, or 15 action potentials with $1 \mathrm{~ms}, 20 \mathrm{~Hz}$ trains of depolarizing current from either -65 or $-60 \mathrm{mV}$. In the presence of $20 \mu \mathrm{M} C \mathrm{Ch}$, these trains are sufficient to cause $C P n$ neurons to persistently fire. $B, C O M$ neurons cannot be driven to fire persistently in the presence of $C C$ even with 50 APs delivered in the same manner. $C$, Counts of COM (red) and $\mathrm{CPn}$ (green) neurons that fire persistently using trains of spikes. $D, E$, In both COM (light red, inset) and (Pn (light green, inset) neurons, a $1 \mathrm{nA}, 10 \mathrm{~ms}$ depolarizing current injection does result in a small $(0-1.5 \mathrm{mV})$ ADP. With the addition of $20 \mu \mathrm{m} \mathrm{CCh}$, most COM neurons ( 4 of 5) exhibit a slight increase in the ADP (dark red, inset). In 1 of 5 COM neurons, a large ADP occurred with CCh (arrow). In CPn neurons (dark green, inset), a much larger ADP is elicited in the presence of $C \mathrm{Ch}$.

(3-6 Hz). During rapid eye movement sleep and exploratory behavior, the hippocampus entrains $\mathrm{MPFC}$ in the theta frequency range (Jones and Wilson, 2005; Siapas et al., 2005). Correlation of activity in the theta frequency range between hippocampus and PFC is associated with learning consolidation and is impaired in a mouse model of schizophrenia (Paz et al., 2008; Sigurdsson et al., 2010). Hippocampal afferents from CA1 and subiculum project to $\mathrm{mPFC}$, in which they make monosynaptic connections to pyramidal neurons (Jay and Witter, 1991; Verwer et al., 1997; Thierry et al., 2000; Delatour and Witter, 2002; Hoover and Vertes, 2007). Whether hippocampal afferents into PFC directly synapse on CPn and/or COM neurons is unknown. Nevertheless, the filtering properties of CPn neurons suggest they may be more sensitive to theta entrainment.

\section{Differences in h-currents may account for subthreshold differences between neuron types}

Measured somatically, the subthreshold responses of CPn and COM neurons suggested that they express different h-currents.
CPn neurons have a faster membrane time constant and lower input resistance than COM neurons. CPn neurons also exhibited more resonance, voltage sag, and rebound and less $\alpha$ EPSP summation. Pharmacological blockade of h-currents with ZD7288 abolishes differences in these parameters (Fig. 5). Importantly, ZD7288 did have a significant effect on the input resistance and membrane time constant of COM neurons (Fig. 5D-G). These data suggest that, although COM neurons do not express many of the dynamic properties typical of h-currents that have been described in other neurons (Hutcheon et al., 1996; Hu et al., 2002; Ulrich, 2002; Nolan et al., 2004; Wang et al., 2006; Narayanan and Johnston, 2007; Zemankovics et al., 2010), they nevertheless do express h-current.

The contribution of h-currents to the dynamic properties of COM and CPn neurons may be distinct for several reasons. Properties of the h-currents COM and CPn neurons may be distinct. The simplest interpretation of these data is that the perisomatic h-currents are sufficient in magnitude in CPn neurons to cause them to resonate, whereas perisomatic h-currents in COM neurons are not. However, the effect of the h-current blocker ZD7288 on the input resistance and membrane potential of CPn and COM neurons was similar. Differences in the h-current may not be solely in magnitude but rather its composition. h-currents comprise different HCN subunits (Santoro et al., 2000; Chen et al., 2001; Ulens and Tytgat, 2001). All four HCN1-HCN4 subunits are expressed in $\mathrm{mPFC}$, although cortical pyramidal neurons tend to primarily express HCN1 and HCN2 (Notomi and Shigemoto, 2004; Day et al., 2005). Sensitivity to ZD7288, gating kinetics, and voltage dependence of heterologously expressed h-channels vary depending on subunit composition (Santoro et al., 2000; Chen et al., 2001; Ulens and Tytgat, 2001; Cheng et al., 2007). Projection-specific expression of h-currents reported in other cortical regions have equivalent $\mathrm{HCN} 1$ and HCN2 mRNA levels (Christophe et al., 2005), suggesting that h-currents in COM and CPn neurons may be distinct as a result of posttranslational modifications. Finally, the differences in the dynamic properties of COM and CPn neurons measured somatically may be attributable to the distribution of h-currents along dendrites. It is important to note that, in this study, all of our recordings were somatic. h-currents are typically dendritically enriched in pyramidal neurons (Magee, 1998; Williams and Stuart, 2000; Berger et al., 2001, 2003; Lörincz et al., 2002; Kole et al., 2006). Furthermore, dynamic measurements such as resonance are highly sensitive to attenuation along dendrites (Narayanan and Johnston, 2008; Williams and Mitchell, 2008). As such, we cannot exclude the possibility that the differences in the dynamic properties of COM and CPn neurons that we observed may be limited to the perisomatic region. The dendritic distribution of $\mathrm{h}$-channels in these different projection neurons remains an important question for future studies.

\section{Efferent-dependent neuromodulation}

Neuromodulation in the PFC contributes to its changes in neural activity during learning and memory (Wang et al., 2007; Santini et al., 2008; Sidiropoulou et al., 2009). However, to understand the effects of neuromodulators on PFC function, its anatomical connections with other brain regions must be taken into account. Enhanced mnemonic persistent activity during the delay period of working memory tasks may be the result of the recruitment of specific populations of projection neurons.

Noradrenergic modulation through $\alpha 2 \mathrm{~A}$ receptors enhances delay activity in PFC and working memory task performance (Wang et al., 2007). This modulation is occluded by infusion of low concentrations of ZD7288 in the prefrontal cortex. In vitro, adrenergic modulation has been shown to enhance both somatic 
and dendritic excitability (Carr et al., 2007; Barth et al., 2008) of PFC neurons. Neuromodulation does not affect all layer V pyramidal neurons equally. The subthreshold responses to dynamic stimuli were changed in CPn but not COM neurons. Furthermore, the excitability of CPn neurons was increased significantly more than COM neurons.

The ability of cholinergic modulation to make neurons fire persistently was also dependent on their projection target. CPn neurons were more likely to fire persistently than COM neurons. This persistent activity was maintained in the presence of synaptic blockers, indicating that it functions independently of any network reverberations. Thus, it appears that neurons projecting subcortically to the pons can be more readily switched into a "persistent" mode, whereas intracortically projecting neurons have a lower propensity to do so. Of course, we cannot exclude the possibility that more intense cholinergic activation or other neuromodulators may be able to drive COM neurons to fire persistently.

In summary, the differing integrative properties of COM and $\mathrm{CPn}$ neurons suggest that they process incoming information in very distinct manners and thus may represent parallel processing of information within the PFC. The distinct responses of COM and $\mathrm{CPn}$ neurons to neuromodulation suggest that they may subserve disparate functions. COM neurons transfer information intracortically between the two hemispheres. The emphasis of this information transfer may be on reliability, making COM neurons integrate and fire faithfully with very little subthreshold filtering of inputs. Although noradrenergic and ACh modulation cause the excitability of COM neurons to increase slightly, they do not fire persistently beyond the depolarizing inputs they receive, thus minimizing the risk of runaway excitation in PFC. In contrast, CPn neurons may act as gates for transferring information. The pons generally serves as a relay station by which cortical information is transferred to the cerebellum (Brodal and Bjaalie, 1992). For example, during trace eyelid conditioning, activity in the pons is both necessary and sufficient to facilitate the association between conditioned and unconditioned stimuli that occur at time intervals too distant for the cerebellum to manage alone (Kalmbach et al., 2009, 2010). In the absence of neuromodulation, CPn neurons integrate inputs with a great deal of subthreshold filtering. However, with the addition of neuromodulators, the integration of CPn neurons becomes similar to COM neurons. Furthermore, cholinergic modulation makes them able to fire persistently beyond their stimulus input, making them well poised to contribute to mnemonic persistent activity that occurs during the delay period of working memory-like tasks.

\section{References}

Andrade R (1991) Cell excitation enhances muscarinic cholinergic responses in rat association cortex. Brain Res 548:81-93.

Arnsten AF (2004) Adrenergic targets for the treatment of cognitive deficits in schizophrenia. Psychopharmacology (Berl) 174:25-31.

Arnsten AF (2006) Stimulants: therapeutic actions in ADHD. Neuropsychopharmacology 31:2376-2383.

Arnsten AFT (2007) Catecholamine and second messenger influences on prefrontal cortical networks of "representational knowledge": a rational bridge between genetics and the symptoms of mental illness. Cereb Cortex 17 [Suppl 1]:i6-i15.

Barth AM, Vizi ES, Zelles T, Lendvai B (2008) 2-Adrenergic receptors modify dendritic spike generation via $\mathrm{HCN}$ channels in the prefrontal cortex. J Neurophysiol 99:394-401.

Berger T, Larkum ME, Lüscher HR (2001) High I(h) channel density in the distal apical dendrite of layer $\mathrm{V}$ pyramidal cells increases bidirectional attenuation of EPSPs. J Neurophysiol 85:855-868.

Berger T, Senn W, Lüscher HR (2003) Hyperpolarization-activated current
Ih disconnects somatic and dendritic spike initiation zones in layer $\mathrm{V}$ pyramidal neurons. J Neurophysiol 90:2428-2437.

Bonilha L, Molnar C, Horner MD, Anderson B, Forster L, George MS, Nahas Z (2008) Neurocognitive deficits and prefrontal cortical atrophy in patients with schizophrenia. Schizophr Res 101:142-151.

Bremner JD, Narayan M, Staib LH, Southwick SM, McGlashan T, Charney DS (1999) Neural correlates of memories of childhood sexual abuse in women with and without posttraumatic stress disorder. Am J Psychiatry 156:1787-1795.

Brodal P, Bjaalie JG (1992) Organization of the pontine nuclei. Neurosci Res 13:83-118.

Brown SP, Hestrin S (2009) Intracortical circuits of pyramidal neurons reflect their long-range axonal targets. Nature 457:1133-1136.

Burgos-Robles A, Vidal-Gonzalez I, Santini E, Quirk GJ (2007) Consolidation of fear extinction requires NMDA receptor-dependent bursting in the ventromedial prefrontal cortex. Neuron 53:871-880.

Bymaster FP, Felder CC (2002) Role of the cholinergic muscarinic system in bipolar disorder and related mechanism of action of antipsychotic agents Mol Psychiatry 7 [Suppl 1]:S57-S63.

Carr DB, Surmeier DJ (2007) M1 muscarinic receptor modulation of Kir2 channels enhances temporal summation of excitatory synaptic potentials in prefrontal cortex pyramidal neurons. J Neurophysiol 97:3432-3438.

Carr DB, Andrews GD, Glen WB, Lavin A (2007) alpha2-Noradrenergic receptors activation enhances excitability and synaptic integration in rat prefrontal cortex pyramidal neurons via inhibition of HCN currents. J Physiol 584:437-450.

Casey BJ, Epstein JN, Buhle J, Liston C, Davidson MC, Tonev ST, Spicer J, Niogi S, Millner AJ, Reiss A, Garrett A, Hinshaw SP, Greenhill LL, Shafritz KM, Vitolo A, Kotler LA, Jarrett MA, Glover G (2007) Frontostriatal connectivity and its role in cognitive control in parent-child dyads with ADHD. Am J Psychiatry 164:1729-1736.

Chen S, Wang J, Siegelbaum SA (2001) Properties of hyperpolarizationactivated pacemaker current defined by coassembly of HCN1 and HCN2 subunits and basal modulation by cyclic nucleotide. J Gen Physiol 117:491-504.

Cheng L, Kinard K, Rajamani R, Sanguinetti MC (2007) Molecular mapping of the binding site for a blocker of hyperpolarization-activated, cyclic nucleotide-modulated pacemaker channels. J Pharmacol Exp Ther 322:931-939.

Christophe E, Doerflinger N, Lavery DJ, Molnár Z, Charpak S, Audinat E (2005) Two populations of layer v pyramidal cells of the mouse neocortex: development and sensitivity to anesthetics. J Neurophysiol 94:3357-3367.

Chudasama Y, Dalley JW, Nathwani F, Bouger P, Robbins TW, Nathwani F (2004) Cholinergic modulation of visual attention and working memory: dissociable effects of basal forebrain 192-IgG-saporin lesions and intraprefrontal infusions of scopolamine. Learn Mem 11:78-86.

Couey JJ, Meredith RM, Spijker S, Poorthuis RB, Smit AB, Brussaard AB, Mansvelder HD (2007) Distributed network actions by nicotine increase the threshold for spike-timing-dependent plasticity in prefrontal cortex. Neuron 54:73-87.

Dalley JW, Cardinal RN, Robbins TW (2004) Prefrontal executive and cognitive functions in rodents: neural and neurochemical substrates. Neurosci Biobehav Rev 28:771-784.

Day M, Carr DB, Ulrich S, Ilijic E, Tkatch T, Surmeier DJ (2005) Dendritic excitability of mouse frontal cortex pyramidal neurons is shaped by the interaction among HCN, Kir2, and Kleak channels. J Neurosci 25:8776-8787.

Delatour B, Witter MP (2002) Projections from the parahippocampal region to the prefrontal cortex in the rat: evidence of multiple pathways. Eur J Neurosci 15:1400-1407.

Dodt HU, Zieglgänsberger W (1990) Visualizing unstained neurons in living brain slices by infrared DIC-videomicroscopy. Brain Res 537:333-336

Dopheide JA, Pliszka SR (2009) Attention-deficit-hyperactivity disorder: an update. Pharmacotherapy 29:656-679.

Egorov AV, Hamam BN, Fransén E, Hasselmo ME, Alonso AA (2002) Graded persistent activity in entorhinal cortex neurons. Nature 420:173-178.

Egorov AV, Unsicker K, von Bohlen und Halbach O (2006) Muscarinic control of graded persistent activity in lateral amygdala neurons. Eur J Neurosci 24:3183-3194. 
Engel AK, Fries P, Singer W (2001) Dynamic predictions: oscillations and synchrony in top-down processing. Nat Rev Neurosci 2:704-716.

Fransén E, Tahvildari B, Egorov AV, Hasselmo ME, Alonso AA (2006) Mechanism of graded persistent cellular activity of entorhinal cortex layer v neurons. Neuron 49:735-746.

Fujisawa S, Amarasingham A, Harrison MT, Buzsáki G (2008) Behaviordependent short-term assembly dynamics in the medial prefrontal cortex. Nat Neurosci 11:823-833.

Gulledge AT, Jaffe DB (1998) Dopamine decreases the excitability of layer V pyramidal cells in the rat prefrontal cortex. J Neurosci 18:9139-9151.

Gulledge AT, Jaffe DB (2001) Multiple effects of dopamine on layer V pyramidal cell excitability in rat prefrontal cortex. J Neurophysiol 86:586-595.

Gulledge AT, Stuart GJ (2003) Action potential initiation and propagation in layer 5 pyramidal neurons of the rat prefrontal cortex: absence of dopamine modulation. J Neurosci 23:11363-11372.

Gulledge AT, Park SB, Kawaguchi Y, Stuart GJ (2007) Heterogeneity of phasic cholinergic signaling in neocortical neurons. J Neurophysiol 97:22152229.

Gulledge AT, Bucci DJ, Zhang SS, Matsui M, Yeh HH (2009) M1 receptors mediate cholinergic modulation of excitability in neocortical pyramidal neurons. J Neurosci 29:9888-9902.

Haj-Dahmane S, Andrade R (1996) Muscarinic activation of a voltagedependent cation nonselective current in rat association cortex. J Neurosci 16:3848-3861.

Haj-Dahmane S, Andrade R (1998) Ionic mechanism of the slow afterdepolarization induced by muscarinic receptor activation in rat prefrontal cortex. J Neurophysiol 80:1197-1210.

Haj-Dahmane S, Andrade R (1999) Muscarinic receptors regulate two different calcium-dependent non-selective cation currents in rat prefrontal cortex. Eur J Neurosci 11:1973-1980.

Hattox AM, Nelson SB (2007) Layer V neurons in mouse cortex projecting to different targets have distinct physiological properties. J Neurophysiol 98:3330-3340.

Herremans AH, Hijzen TH, Olivier B (1997) Effects of cholinergic drug infusions into the dorsal part of the medial prefrontal cortex on delayed conditional discrimination performance in the rat. Behav Brain Res 84:291-299.

Heys JG, Giocomo LM, Hasselmo ME (2010) Cholinergic modulation of the resonance properties of stellate cells in layer II of medial entorhinal cortex. J Neurophysiol 104:258-270.

Hoover WB, Vertes RP (2007) Anatomical analysis of afferent projections to the medial prefrontal cortex in the rat. Brain Struct Funct 212:149-179.

Hu H, Vervaeke K, Storm JF (2002) Two forms of electrical resonance at theta frequencies, generated by M-current, $\mathrm{h}$-current and persistent $\mathrm{Na}^{+}$ current in rat hippocampal pyramidal cells. J Physiol 545:783-805.

Hu H, Vervaeke K, Storm JF (2007) M-channels (Kv7/KCNQ channels) that regulate synaptic integration, excitability, and spike pattern of CA1 pyramidal cells are located in the perisomatic region. J Neurosci 27:1853-1867.

Hu H, Vervaeke K, Graham LJ, Storm JF (2009) Complementary theta resonance filtering by two spatially segregated mechanisms in CA1 hippocampal pyramidal neurons. J Neurosci 29:14472-14483.

Hutcheon B, Yarom Y (2000) Resonance, oscillation and the intrinsic frequency preferences of neurons. Trends Neurosci 23:216-222.

Hutcheon B, Miura RM, Puil E (1996) Subthreshold membrane resonance in neocortical neurons. J Neurophysiol 76:683-697.

Hyde TM, Crook JM (2001) Cholinergic systems and schizophrenia: primary pathology or epiphenomena? J Chem Neuroanat 22:53-63.

Ikonomovic MD, Abrahamson EE, Isanski BA, Wuu J, Mufson EJ, DeKosky ST (2007) Superior frontal cortex cholinergic axon density in mild cognitive impairment and early Alzheimer disease. Arch Neurol 64:1312-1317.

Jay TM, Witter MP (1991) Distribution of hippocampal CAl and subicular efferents in the prefrontal cortex of the rat studied by means of anterograde transport of Phaseolus vulgaris-leucoagglutinin. J Comp Neurol 313:574-586.

Jones MW, Wilson MA (2005) Phase precession of medial prefrontal cortical activity relative to the hippocampal theta rhythm. Hippocampus 15:867-873.

Kalmbach BE, Ohyama T, Kreider JC, Riusech F, Mauk MD (2009) Interactions between prefrontal cortex and cerebellum revealed by trace eyelid conditioning. Learn Mem 16:86-95.
Kalmbach BE, Ohyama T, Mauk MD (2010) Temporal patterns of inputs to cerebellum necessary and sufficient for trace eyelid conditioning. J Neurophysiol 104:627-640.

Kapur S (2003) Psychosis as a state of aberrant salience: a framework linking biology, phenomenology, and pharmacology in schizophrenia. Am J Psychiatry 160:13-23.

Kasper EM, Larkman AU, Lübke J, Blakemore C (1994a) Pyramidal neurons in layer 5 of the rat visual cortex. I. Correlation among cell morphology, intrinsic electrophysiological properties, and axon targets. J Comp Neurol 339:459-474.

Kasper EM, Larkman AU, Lübke J, Blakemore C (1994b) Pyramidal neurons in layer 5 of the rat visual cortex. II. Development of electrophysiological properties. J Comp Neurol 339:475-494.

Klimesch W, Freunberger R, Sauseng P (2010) Oscillatory mechanisms of process binding in memory. Neurosci Biobehav Rev 34:1002-1014.

Kole MH, Hallermann S, Stuart GJ (2006) Single Ih channels in pyramidal neuron dendrites: properties, distribution, and impact on action potential output. J Neurosci 26:1677-1687.

Kruse MS, Prémont J, Krebs MO, Jay TM (2009) Interaction of dopamine D1 with NMDA NR1 receptors in rat prefrontal cortex. Eur Neuropsychopharmacol 19:296-304.

Law-Tho D, Crepel F, Hirsch JC (1993) Noradrenaline decreases transmission of NMDA- and non-NMDA-receptor mediated monosynaptic EPSPs in rat prefrontal neurons in vitro. Eur J Neurosci 5:1494-1500.

Le Bé JV, Silberberg G, Wang Y, Markram H (2007) Morphological, electrophysiological, and synaptic properties of corticocallosal pyramidal cells in the neonatal rat neocortex. Cereb Cortex 17:2204-2213.

Lewis DA, González-Burgos G (2008) Neuroplasticity of neocortical circuits in schizophrenia. Neuropsychopharmacology 33:141-165.

Lörincz A, Notomi T, Tamás G, Shigemoto R, Nusser Z (2002) Polarized and compartment-dependent distribution of HCN1 in pyramidal cell dendrites. Nat Neurosci 5:1185-1193.

Magee JC (1998) Dendritic hyperpolarization-activated currents modify the integrative properties of hippocampal CAl pyramidal neurons. J Neurosci 18:7613-7624.

Marder E, Abbott LF, Turrigiano GG, Liu Z, Golowasch J (1996) Memory from the dynamics of intrinsic membrane currents. Proc Natl Acad Sci U S A 93:13481-13486.

Marsh R, Zhu H, Wang Z, Skudlarski P, Peterson BS (2007) A developmental fMRI study of self-regulatory control in Tourette's syndrome. Am J Psychiatry 164:955-966.

McCormick DA, Prince DA (1985) Two types of muscarinic response to acetylcholine in mammalian cortical neurons. Proc Natl Acad Sci U S A 82:6344-6348.

Miller EK (2000) The prefrontal cortex and cognitive control. Nat Rev Neurosci 1:59-65.

Molnár Z, Cheung AF (2006) Towards the classification of subpopulations of layer V pyramidal projection neurons. Neurosci Res 55:105-115.

Morishima M, Kawaguchi Y (2006) Recurrent connection patterns of corticostriatal pyramidal cells in frontal cortex. J Neurosci 26:4394-4405.

Narayanan NS, Laubach M (2006) Top-down control of motor cortex ensembles by dorsomedial prefrontal cortex. Neuron 52:921-931.

Narayanan R, Johnston D (2007) Long-term potentiation in rat hippocampal neurons is accompanied by spatially widespread changes in intrinsic oscillatory dynamics and excitability. Neuron 56:1061-1075.

Narayanan R, Johnston D (2008) The h channel mediates location dependence and plasticity of intrinsic phase response in rat hippocampal neurons. J Neurosci 28:5846-5860.

Nolan MF, Malleret G, Dudman JT, Buhl DL, Santoro B, Gibbs E, Vronskaya S, Buzsáki G, Siegelbaum SA, Kandel ER, Morozov A (2004) A behavioral role for dendritic integration: HCN1 channels constrain spatial memory and plasticity at inputs to distal dendrites of CA1 pyramidal neurons. Cell 119:719-732.

Notomi T, Shigemoto R (2004) Immunohistochemical localization of Ih channel subunits, HCN1-4, in the rat brain. J Comp Neurol 471:241-276.

Otsuka T, Kawaguchi Y (2008) Firing-pattern-dependent specificity of cortical excitatory feed-forward subnetworks. J Neurosci 28:11186-11195.

Parikh V, Kozak R, Martinez V, Sarter M (2007) Prefrontal acetylcholine release controls cue detection on multiple timescales. Neuron 56:141-154.

Paxinos G, Watson C (1993) The rat brain in stereotaxic coordinates. San Diego: Academic. 
Paz R, Bauer EP, Paré D (2008) Theta synchronizes the activity of medial prefrontal neurons during learning. Learn Mem 15:524-531.

Puil E, Gimbarzevsky B, Miura RM (1986) Quantification of membrane properties of trigeminal root ganglion neurons in guinea pigs. J Neurophysiol 55:995-1016.

Rosenkranz JA, Johnston D (2007) State-dependent modulation of amygdala inputs by dopamine-induced enhancement of sodium currents in layer V entorhinal cortex. J Neurosci 27:7054-7069.

Santini E, Quirk GJ, Porter JT (2008) Fear conditioning and extinction differentially modify the intrinsic excitability of infralimbic neurons. J Neurosci 28:4028-4036.

Santoro B, Chen S, Luthi A, Pavlidis P, Shumyatsky GP, Tibbs GR, Siegelbaum SA (2000) Molecular and functional heterogeneity of hyperpolarization-activated pacemaker channels in the mouse CNS. J Neurosci 20:5264-5275.

Scahill L (2009) Alpha-2 adrenergic agonists in children with inattention, hyperactivity and impulsiveness. CNS Drugs 23 [Suppl 1]:43-49.

Shin LM, Orr SP, Carson MA, Rauch SL, Macklin ML, Lasko NB, Peters PM, Metzger LJ, Dougherty DD, Cannistraro PA, Alpert NM, Fischman AJ, Pitman RK (2004) Regional cerebral blood flow in the amygdala and medial prefrontal cortex during traumatic imagery in male and female Vietnam veterans with PTSD. Arch Gen Psychiatry 61:168-176.

Sholl DA (1953) Dendritic organization in the neurons of the visual and motor cortices of the cat. J Anat 87:387-406.

Siapas AG, Lubenov EV, Wilson MA (2005) Prefrontal phase locking to hippocampal theta oscillations. Neuron 46:141-151.

Sidiropoulou K, Lu FM, Fowler MA, Xiao R, Phillips C, Ozkan ED, Zhu MX, White FJ, Cooper DC (2009) Dopamine modulates an mGluR5mediated depolarization underlying prefrontal persistent activity. Nat Neurosci 12:190-199.

Sigurdsson T, Stark KL, Karayiorgou M, Gogos JA, Gordon JA (2010) Impaired hippocampal-prefrontal synchrony in a genetic mouse model of schizophrenia. Nature 464:763-767.

Strawn JR, Geracioti TD Jr (2008) Noradrenergic dysfunction and the psychopharmacology of posttraumatic stress disorder. Depress Anxiety 25:260-271.

Stuart GJ, Dodt HU, Sakmann B (1993) Patch-clamp recordings from the soma and dendrites of neurons in brain slices using infrared video microscopy. Pflugers Arch 423:511-518.

Thierry AM, Gioanni Y, Dégénétais E, Glowinski J (2000) Hippocampoprefrontal cortex pathway: anatomical and electrophysiological characteristics. Hippocampus 10:411-419.

Ulens C, Tytgat J (2001) Functional heteromerization of HCN1 and HCN2 pacemaker channels. J Biol Chem 276:6069-6072.
Ulrich D (2002) Dendritic resonance in rat neocortical pyramidal cells. J Neurophysiol 87:2753-2759.

Verwer RW, Meijer RJ, Van Uum HF, Witter MP (1997) Collateral projections from the rat hippocampal formation to the lateral and medial prefrontal cortex. Hippocampus 7:397-402.

Vijayraghavan S, Wang M, Birnbaum SG, Williams GV, Arnsten AF (2007) Inverted-U dopamine D1 receptor actions on prefrontal neurons engaged in working memory. Nat Neurosci 10:376-384.

Wall PM, Flinn J, Messier C (2001) Infralimbic muscarinic M1 receptors modulate anxiety-like behaviour and spontaneous working memory in mice. Psychopharmacology 155:58-68.

Wang H, Stradtman GG 3rd, Wang XJ, Gao WJ (2008) A specialized NMDA receptor function in layer 5 recurrent microcircuitry of the adult rat prefrontal cortex. Proc Natl Acad Sci U S A 105:16791-16796.

Wang M, Ramos BP, Paspalas CD, Shu Y, Simen A, Duque A, Vijayraghavan S, Brennan A, Dudley A, Nou E, Mazer JA, McCormick DA, Arnsten AF (2007) Alpha2A-adrenoceptors strengthen working memory networks by inhibiting cAMP-HCN channel signaling in prefrontal cortex. Cell 129:397-410.

Wang WT, Wan YH, Zhu JL, Lei GS, Wang YY, Zhang P, Hu SJ (2006) Theta-frequency membrane resonance and its ionic mechanisms in rat subicular pyramidal neurons. Neuroscience 140:45-55.

Wang XJ (2001) Synaptic reverberation underlying mnemonic persistent activity. Trends Neurosci 24:455-463.

Wang Z, McCormick DA (1993) Control of firing mode of corticotectal and corticopontine layer $\mathrm{V}$ burst-generating neurons by norepinephrine, acetylcholine, and 1S,3R-ACPD. J Neurosci 13:2199-2216.

Williams SR, Mitchell SJ (2008) Direct measurement of somatic voltage clamp errors in central neurons. Nat Neurosci 11:790-798.

Williams SR, Stuart GJ (2000) Site independence of EPSP time course is mediated by dendritic $\mathrm{I}(\mathrm{h})$ in neocortical pyramidal neurons. J Neurophysiol 83:3177-3182.

Yang CR, Seamans JK (1996) Dopamine $\mathrm{D}_{1}$ receptor actions in layers V-VI rat prefrontal cortex neurons in vitro: modulation of dendritic-somatic signal integration. J Neurosci 16:1922-1935.

Zemankovics R, Káli S, Paulsen O, Freund TF, Hájos N (2010) Differences in subthreshold resonance of hippocampal pyramidal cells and interneurons: the role of h-current and passive membrane characteristics. J Physiol 588:2109-2132.

Zhang Z, Séguéla P (2010) Metabotropic induction of persistent activity in layers II/III of anterior cingulate cortex. Cereb Cortex. Advance online publication. Retrieved November 7, 2010. doi:10.1093/cercor/bhq043. 